\title{
The Role of Bioactive Lipids and Statins in COVID-19 Disease and Their Use in the Therapeutic Approach. Are These Effective?
}

\author{
Sivaropoulos Nektarios ${ }^{1}$, Aligizakis Eftychios ${ }^{2}$, Gryllaki Nikoletta ${ }^{3}$ \\ ${ }^{1}$ Primary Care Health Center of Spili, Crete, Greek \\ ${ }^{2}$ Primary Care Health Center of Kandanos, Crete, Greek \\ ${ }^{3}$ Primary Care Health Center of Chania, Crete, Greek \\ Email: ^nektsivar@gmail.com, aligizak@gmail.com,ngrillaki@gmail.com
}

How to cite this paper: Nektarios, S., Eftychios, A. and Nikoletta, G. (2021) The Role of Bioactive Lipids and Statins in COVID-19 Disease and Their Use in the Therapeutic Approach. Are These Effective? Journal of Biosciences and Medicines, 9, 143-173.

https://doi.org/10.4236/jbm.2021.97015

Received: April 19, 2021

Accepted: July 18, 2021

Published: July 21, 2021

Copyright $\odot 2021$ by author(s) and Scientific Research Publishing Inc. This work is licensed under the Creative Commons Attribution International License (CC BY 4.0).

http://creativecommons.org/licenses/by/4.0/

\section{(c) (i) Open Access}

\begin{abstract}
COVID-19 disease constitutes a significant threat to human existence worldwide due to the increased transmissibility, morbidity and mortality caused by the still unknown SARS-COV2 virus. A critical issue is the lack of effectiveness of drug options. In our research, a literature review, we explore the role of bioactive lipids and statins can play, as a main or adjunctive treatment in the COVID-19. We reviewed 150 articles in the Databases (PubMed/MEDLINE, Google Scholar, Embassy and Cochrane) relatives of the use of bioactive lipids and statins in severe COVID-19 disease and we selected 117 articles that fit with our research question. So, our research constitutes a bibliography review of 117 articles, finally. The administration of exogenous bioactive lipids (BALs), Omega $3 \mathrm{EPA}$, DHA supplements induces the suppression of pro-inflammatory cytokines, the prevention of cytokine storm and enhancing the therapeutic benefit by accelerating recovery. Therefore, they potentially reduce the need for ICU hospitalization and the number of intensive care unit days of stay, accelerating recovery thus also numerically reducing critical cases. The possible harms of lipids should be considered. There are positive and negative effects regarding the use of statins. According to the literature, Statins offer beneficial effects on COVID-19 disease. For de novo statin use in COVID-19 patients, the Benefit/Risk ratio should be taken into account. In conclusion, although lipids and statins seem to benefit patients with severe COVID-19 disease, nevertheless, more double blind randomized studies are needed to determine their safety and efficacy profile.
\end{abstract}

\section{Keywords}

Bioactive Lipids/Statins/Therapeutic Options of Severe COVID-19 


\section{How This Fits in}

It's already known that bioactive lipids and statins possess anti-inflammatory, anticoagulant and antiplatelet activity, but we are unaware whether they can be used as COVID-19 severe disease therapy. In our study we collected information on additional lipid and statin actions that could potentially benefit people with severe COVID-19 disease while we are also investigated possible harms that they can cause during COVID-19 disease and we explore if there be any evidence that statins may prevent infectious diseases and whether to discontinue statin therapy in patients with high cardiovascular risk or cardiovascular diseases when the same patients have been infected by SARS-COV2.

\section{Introduction}

COVID-19 disease, caused by the Severe Acute Respiratory Syndrome Coronavirus 2 (SARS-COV2), has been declared us pandemic by the WHO, in 11 March of 2020, while the recent eruption was reported in Wuhan, China, in December 2019, with millions of confirmed cases around the world. At a news briefing, WHO Director-General, Dr. Tedros Adhanom, noted that over the past 2 weeks, the number of cases outside China increased 13-fold and the number of countries with cases increased threefold [1]. A brief review COVID-19 disease is presented in Figure 1.

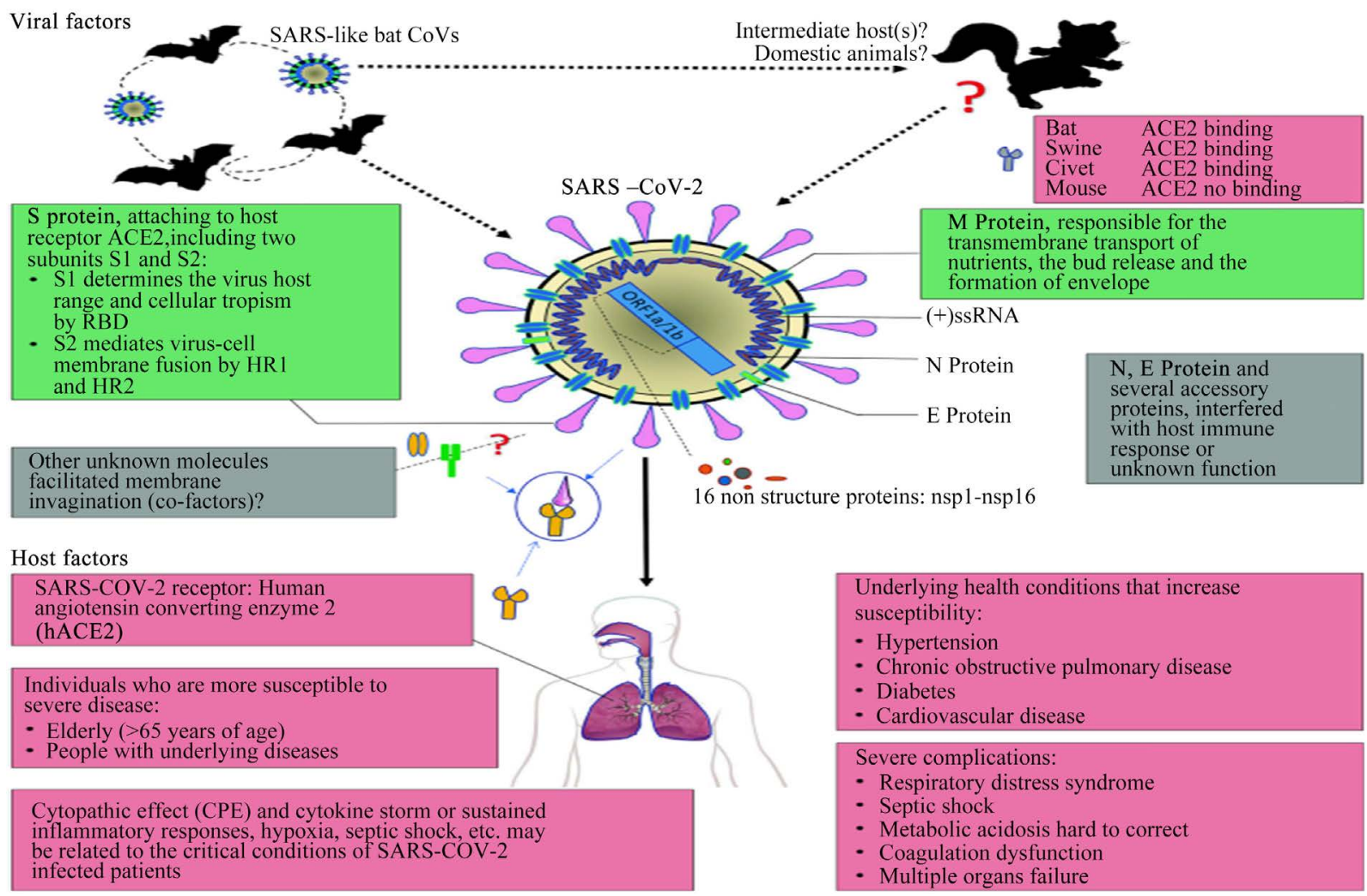

Figure 1. The origin, transmission and clinical therapies on coronavirus disease 2019 (COVID-19) outbreak-Guo, et al. (2020) The origin, transmission and clinical therapies on coronavirus disease 2019 (COVID-19) outbreak-an update on the status Military Medical Research 2020, 7:11 [2]. 
Primarily, COVID-19 was noted as a respiratory disease. Lungs and lower respiratory tracts are mainly affected and patient's clinical manifestations were dry cough, fever, shortness of breath, dyspnea [3]. The novel coronavirus can also invade several organ systems and affect the heart, kidneys, liver, nervous system, blood vessels, and skin. Cytokine storm is considering the underlying condition for extra pulmonary adverse effects. The excessive release of cytokines can cause cellular and tissue injuries [4]. Finally, COVID-19 disease produces multiorgan system damages as depicted in Figure 2.

The severe progression of the disease leads to acute lung injury (ALI), acute respiratory distress syndrome (ARDS), Sepsis, Heart Failure and Sudden Cardiac Arrest within a few days. It manifests itself either with mild symptoms of virus or with critical COVID-19 disease, resulting from a multi-systemic septic-hyper-inflammatory reaction produced by the prevalence of cytokine storm against anti-inflammatory agents (reduced biosynthesis of SPMs, derived from Omega-3 long chain PUFAs, EPA and DHA), which lead to the inflammatory solution and which in turn promotes Immunomodulatory Dyslipoproteinemia proportional to the severity of COVID-19 [6].

The development of Dyslipidemia begins with the early stages of the disease and gradually worsens depending on changes in CRP and IL-6. TSPMs (Specialized Pro-resolving Lipid Mediators) bioactive lipids (Lipoxins, Resolvins, Maresins, Protectins) produced in phagocytes by the precursors EPA and DHA molecules, offer notable beneficial effects on COVID-19 disease. They suppress the

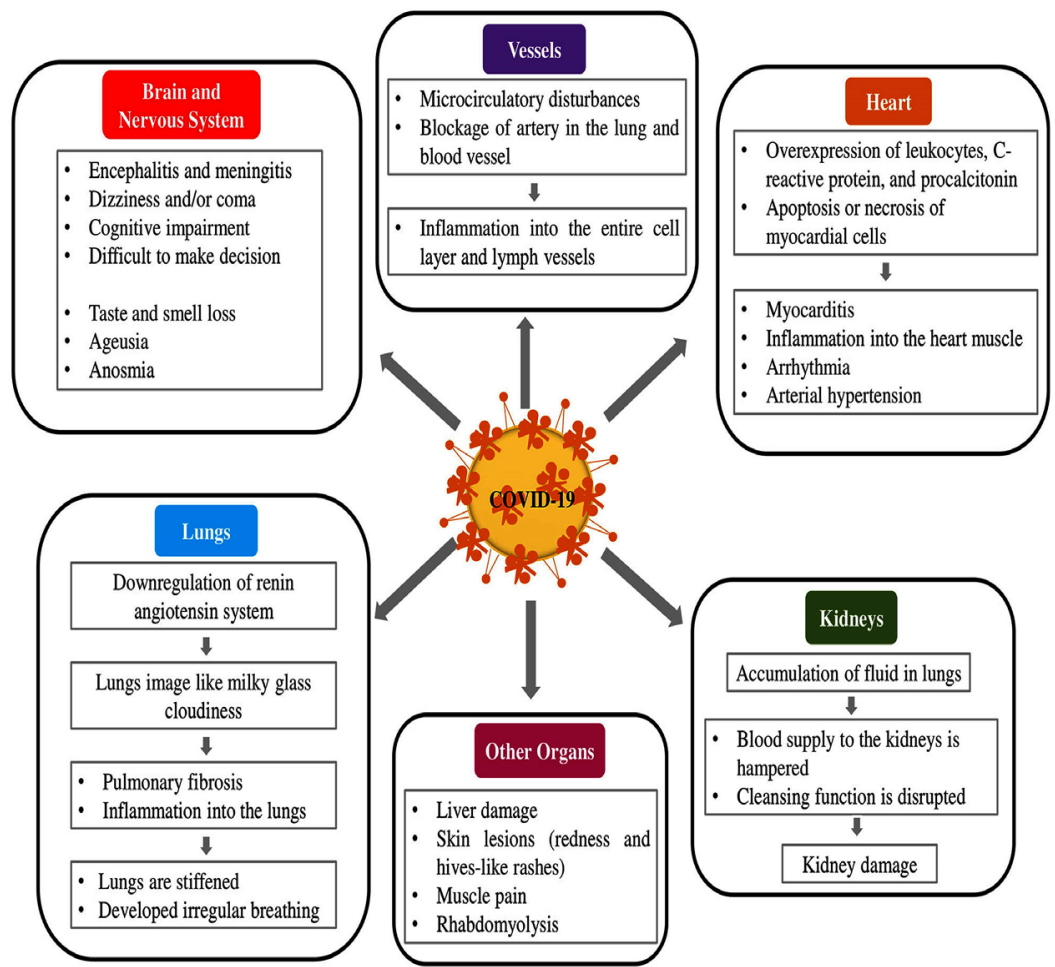

Figure 2. COVID-19 adverse effects on human systems. Hossain, F., Hasana, Sh., Mamun, A.A., et al. (2020) COVID-19 Outbreak: Pathogenesis, Current Therapies and Potentials for Future Management. Front. In Pharmacol, 11, Article 563478 [5]. 
activity of ACE2, blunt the bond, protein-S (spike) of the virus in ACE2 receptors of cell membranes, indirectly suppressing the expression of ACE2 receptors event which leads to their reduced availability and reduces ATII production, contribute to the solution of the cell membrane and the degradation of the viral envelope and inactivate viruses, deregulate oxidative phosphorylation and participate in the transfer of amino acids, as is depicted in Figure 3 [7] [8] [9] [10].

On the contrary, a study of Rogero e al (Rogero et al., 2020) has reported that supplements EPA and DHA could cause harmful effects. They can make cell membrane phospholipids and triglycerides more susceptible to non-enzymatic oxidation mediated by reactive oxygen species (ROS), leading to the formation of potentially toxic oxidation products us $\alpha, \beta$-polyunsatured lipid aldehydes (MDA, 4-HNE, 4-HHE, IsoPs, NeuroPs) and increasing the oxidative stress, already pre-installed by SARS-C RNA infection, leading to cell apoptosis, us result of mitochondrial dysfunction, loss of immune function and increase of viral replication, like is indicated in Figure 3 [11].

Regarding statins, it is already known, they have pleiotropic immunoregulatory anti-inflammatory, antithrombotic and antioxidant effects like depicts Figure 5. So they likely could be a helpful therapy to tackle the complicate issue of cardiovascular COVID-19 complications but also potentially they would be considered able to benefit patients under conditions of morbidity and mortality due to SARS-COV2.

\section{POTENTIAL BENEFITS}

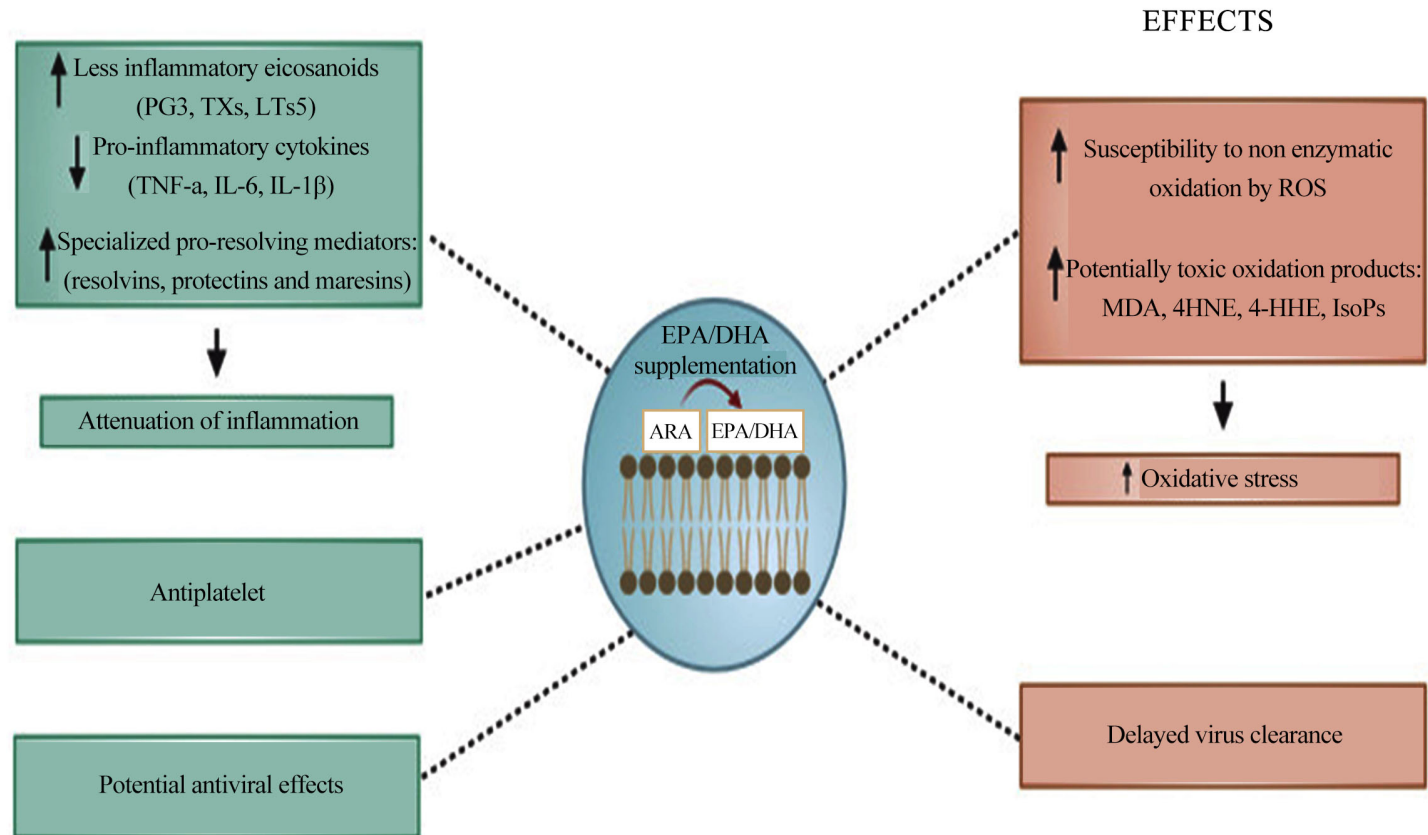

Figure 3. Potential effects of EPA and DHA supplementation in critical SARS-CoV-2 infected patients. PG3: prostaglandin E3, TXs: thromboxanes; LTs5: 5-series leukotrienes; TFN- $\alpha$ : tumor necrosis factor- $\alpha$; IL-6: interleukin 6; IL-1 $\beta$ : interleukin $1 \beta$; ROS: reactive oxygen species; MDA: malondialdehyde; 4-HNE: hydroxylnonenal; 4-HHE: 4-hydroxy-hexenal; ISoPs: isoprostanes. Ferrari, F., Santos, R. (2021) Statins and COVID-19: To suspend or not to suspend? That is the Question. Arq Bras Cardiol, 116, 1, 147-152. 
About Statin actions on COVID-19, it has been observed, due to other corona virus infections, a decrease of myeloid differentiation by primary protein (MYD), lead to poor prognosis; The fact that statins are known TLR-MyD88 pathway antagonists, has led some to speculate that use of statins might interfere with innate immune response, and worsen SARS-CoV2 infection. Contrary, Statins can stabilize MYD88 levels in the presence of external pressures, meaning they elevate their roles in protecting COVID-19 patients from the formation of major inflammatory responses [12].

However, the use of statins could promote possible harms in the COVID-19 disease patients, thus we must not neglect this data, us they increase the ATII levels, thus enhancing the entry of viruses into cells. Statins cause myositis and liver damage, interact with antiviral and PPIs drugs metabolized in P450 cytochrome, so statin levels become toxic and increase the risk of rhabdomyolysis and myopathy [12].

Although various treatments like antivirus medicines, corticosteroids, immunomodulatory treatments, antibiotics have been proposed, however no specific treatment has not yet established, therefore is a crucial need to research on supportive therapies like bioactive lipids and statins aimed at further enhancing efficacy of the actual treatments of COVID-19 disease.

\section{Disegn and Setting}

We realized a descriptive review of the existing literature and used the databases (Google Scholar, Cochrane, EMBASY, PUBMED/MEDLINE), from October 2020 to June 2021, initially consulted 150 articles of various types like Cohort studies, Reviews, Metanalysis, case reports, letters to editors, Randomized Control Studies, from which, in base, of inclusion criteria that were the keywords bioactive lipids/statins/COVID-19 disease and exclusion criteria as we have defined, the age of the articles (our articles accepted refer to knowledge and data of the last 20 years, while the majority of them included in the literature of the last two years), the content of them (accepted various articles providing general information about bioactive lipids and statins actions, while there was a particular interest of articles with explicit reference to COVID-19), we finally selected 117 articles that better fit to our research question.

\section{Methods}

Our study is a literature review. We implemented a bibliography review of 150 articles in the Databases (PubMed, Embassy, MEDLINE, Google Scholar and Cochrane), regarding the link of bioactive lipids, statins with COVID-19 therapy, the period from October 2020 to June 2021 and we selected 117 articles harmonized with our research question.

\section{PUFAs and Statins in COVID-19 Disease}

\subsection{Pros and Cons of PUFAs in COVID-19 Disease}

Omega3FAs represent an important class of fats known as polyunsaturated fatty 
acids (PUFAs). (PUFAs) are abundantly present in nature and their supplements are note as GRAS. A recent study showed that more than $90 \%$ of American people consumed less than the recommended optimal value for omega-3 FAs in the diet $(0.17 \mathrm{~g} /$ day) [13].

Omega-3 FA is incorporated throughout the body into the bi-phospholipid layer of the cell membrane of neutrophils and produces different mediators [14] [23].

So, during viral infections, the release of different inflammatory cytokines and chemokines is regulated by mediators as Omega-3 polyunsaturated fatty acids (w-3 PUFAs) [15] [16].

Specially, Long chain PUFAs Omega 3 and Omega 6 are precursors of Resolvins/ Protectins and Prostaglandins/Leukotrienes respectively. These are considerable inflammatory and adaptive immune response mediators [17]. So PUFAs exhibit a significant anti-inflammatory activity and mitigate the inflammation as well as strengthening the immune response, which alleviates severe acute clinical effects [18], due to viral infections. Omega 3 PUFAs can reduce the expression of ERK1/2 MAPK, NF-kB, and COX-2 [19]. Additionally, oral administration of Omega 3 PUFAs, inhibits ROS generation and down regulates the level of TNF-a, IL-1b, IL-6, and IL-8 during viral infection [20]. Omega-3 FAs weaken the antiviral response of $\mathrm{CD} 8 \mathrm{~T}$ cells and thereby could potentially be used to modulate cytokine responses to viral invaders [21]. The functions of bioactive lipids and other medicines that are able to use different pathways involving lipids actions, related to inflammation, oxidation processes and mainly to immunity adjustments during COVID-19 are depicted in Figure 4.

In patients with AIDS, researchers found a special lack of Omega-3 long-chain PUFAs among lipids, abundant in fish oils [22]. It was observed that Protectin D1, derived by PUFA, may reduce also the influenza virus replication and the combination of Protectin D1 with Peramivir reduced the mortality rate of mice suffering from the Flu [23].

Additionally, one of the major causes of death in patients infected with SARS during COVID-19 is multiorgan failure, which is a result of immune system overdrive causing cytokine storms. The Omega-3 FA is known to produce less pro-inflammatory cytokines, therefore increasing Omega-3 FA intake in the diet or supplementation could decrease viral entry, promote better immune function, and decrease severity among those who have been diagnosed with COVID-19 [24].

The effects of Omega-3 during active inflammation and oxidative stress are significant. Omega-3 FA (fatty acid) plays a role in the host cellular membrane which regulates membrane fluidity and intricate lipid raft assembling in the cell membrane. [21] Omega-3 FA is incorporated throughout the body into the bi-phospholipid layer of the cell membrane of neutrophils and produces different mediators. [14] For that reason, if the injury occurs the by omega 3 products of those cell membranes may produce less inflammatory provoking mediators compared to omega-6, which is more prevalent in the American diet [25]. 


\section{Immunomodulatory lipids}

Oxidized phospholipids, S1P, and eicosanoids derived from arachidonic acid can affect antiviral immune responses. Drugs (red boxes) target some of these pathways and may have application in treating COVID-19.

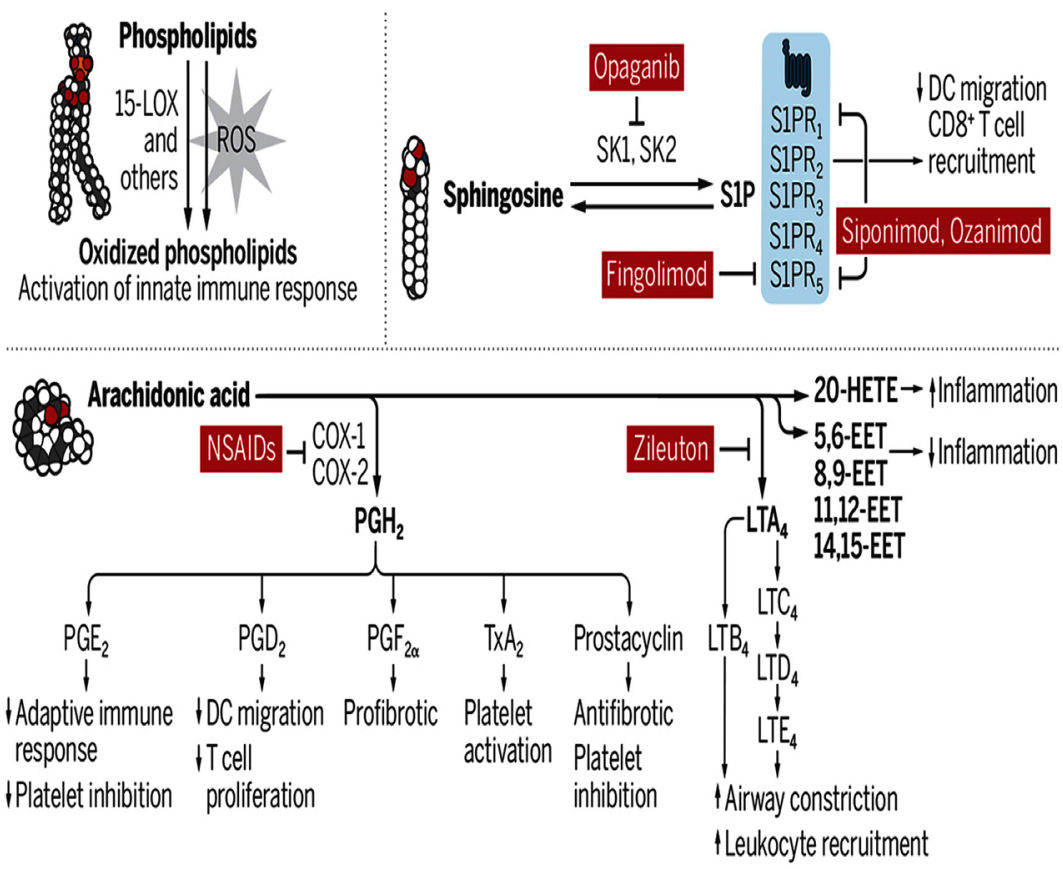

15-LOX, 15-lipoxygenase; COX, cyclooxygenase; DC, dendritic cell; EET, epoxyeicosatrienoic acid; 20-HETE, 20-hydroxyeicosatetraenoic acid; IFN, interferon: LT, leukotriene; NSAID, nonsteroidal anti-inflammatory drug; PG, prostaglandin; ROS, reactive oxygen species; SIP, sphingosine-1. phosphate; SIPR, SIP receptor; SK, sphingosine kinase; TXA2, thromboxane $A_{2}$.

Figure 4. Bioactive lipids and Immunomodulatory, antiflammatory processes during COVID-19. Potential therapies capable of using this pathways and benefit COVID-19 patients. Theken, N. K., Fitzgerald, A.G. (2021) bioactive lipids in antiviral immunity. Science, 371, 6526, 237-238.

Omega-3 FAs improve the function of the macrophages by secreting cytokines and chemokines, promoting the ability of phagocytosis, and activating macrophages by polarization [26]. Omega-3 FAs are also known to down-regulate Nuclear Factor $-\kappa$ Beta (NF $\kappa$ B). NF- $\kappa \mathrm{B}$ is considered to be a transcription factor involved in cell signaling to initiate an inflammatory response by the innate immune system. The study shows that fish oil enhances antiviral response by inducing interferon (IFN) which inhibits viral replication. [26] Omega-3 FAs weaken the antiviral response of CD8 T cells and thereby could potentially be used to modulate cytokine responses to viral invaders [21].

In this study, omega-3 FAs reduced neutrophils infiltration, pro-inflammatory mediators, and classical monocytes while it enhanced non-classical monocytes/macrophages recruitment and efferocytosis in sepsis [27].

Saedisomeolia et al conducted a study to determine the anti-inflammatory properties of DHA and EPA in airway epithelial cells infected with Rhinovirus. The investigators found that DHA significantly reduced the release of IL- 6 and IP-10 from the cells infected with different strains of rhinovirus [28]. 
Omega-3 FAs have been found to exhibit antioxidant activity through various mechanisms including up regulating nuclear factor erythroid 2-related factor 2 (NRF2) mediated antioxidant effects, reducing F2 isoprostanes formed during the oxidation of Arachidonic acid, inducing PPAR $\gamma$ and modulating toll-like receptor 4 (TLR4) receptors which all lead to a reduction in $\kappa \beta$ phosphorylation and thus reduce NF- $\kappa \beta$ which in turn reduces inflammatory markers like IL-6, $\mathrm{TNF} \alpha$, and tissue growth factor beta (TGF $\beta$ ) [29] [30] [31].

They also induce mitogen activated protein kinase (MAPK) phosphatases and up regulate glutathione also known as GSH, which is an antioxidant molecule, and up regulate genes responsible for the production of heme-oxygenase, which is cytoprotective. N-3 fatty acids also inhibit lipid peroxidation [29] [30] [31].

Additionally, the influence of Omega-3 on the immune system, during infections is crucial. Omega-3 FAs regulates the activation of immune cells specifically in macrophages, neutrophils, T-cells, B-cells, dendritic cells, natural killer cells, mast cells, basophiles, and eosinophils. Omega-3 FAs also increase the function of neutrophils. A study showed that omega-3 FAs incorporate phospholipids of the cell membrane of neutrophils and produce different mediators such as prostaglandins, leukotrienes, and Maresins [14].

Neutrophils strengthen the immune function by promoting neutrophils migration, phagocytic capacity, and production of reactive free radicals to kill $\mathrm{mi}-$ crobes. Omega-3 FAs help activate the function of $\mathrm{T}$ cells by promoting antigen-presenting cells (APC). That promotes activation of different subgroups of $\mathrm{T}$ cells such as CD4 cells, Th17 cells, and regulatory T cells. The study claims that omega-3 FAs also increase the population of B cells in the study mice [14].

Omega-3 improves the function of the macrophages by secreting cytokines and chemokines, promoting the ability of phagocytosis, and activating macrophages by polarization [32].

Moreover, the omega-3 FA has appeared to block the activity of NF- $\kappa \mathrm{B}$ through decreasing the degradation of the inhibitory subunit of the NF- $\kappa$ B called IkB, Since NF- $\kappa$ B is responsible for cytokine production in immune cells, by blocking that pathway, its decreasing cytokine storm, and complication [33].

Omega-3 FAs are also known to down-regulate NF- $\kappa \mathrm{B}$. NF- $\kappa \mathrm{B}$ is considered to be a transcription factor involved in cell signaling to initiate an inflammatory response by the innate immune system Omega- 3 up regulates vagal response which in turn down-regulates inflammation and cytokine production [34].

During viral infection, a study shows that fish oil enhances antiviral response by inducing interferon (IFN) which inhibits viral replication [31]. The anti-inflammatory effect by omega-3 FAs is stronger in DHA compared to that of EPA, and their secretion of cytokines IL-10 is further increased by omega-3. Omega-3 FAs weaken the antiviral response by CD8 T cells and could potentially be used to modulate cytokine responses as antiviral responses, and this process is further explained in Figure 3 [35]. CD8 T cells are responsible for fighting against viruses by inducing the production of different cytokines in the 
body, such as Tumor Necrosis Factor-alpha (TNF-alpha) and granzyme B. However, the surge of cytokines by CD8 T cells to defend influenza viruses impose unintended lung damage and further deteriorate the clinical outcome [34].

Besides, Omega-3 health benefits are encompassing various organ systems and diseases including cardiovascular disease, cancer, Alzheimer's disease, diabetes, dementia, depression, maternal and child health and visual and neurological development, and. Numerous studies have been done that enumerate the reduction in clinical disease rates and mortality rates in patients suffering from a vast array of diseases [36].

Although the role of $\omega$-3 supplementation in ARDS needs to be further elucidated, its vital role in reducing reactive oxygen species and pro-inflammatory cytokines, such as TNF- $\alpha$, IL- $1 \beta$, IL-6, and IL-8, is widely documented. Therefore, $\omega-3$ PUFAs could be considered for potential interventions for COVID-19 [36].

Except of their antioxidant and anti-inflammatory properties, which benefit mainly the cardiovascular system and their vasoprotective actions, $n-3$ PUFAs are also responsible of side effects [37].

Oxidation of n-3 PUFAs could develop cytotoxicity, genotoxic effects reducing nutritional values of n-3 PUFAs. [38] [39] N-3 PUFAs tend to oxidation leading to peroxyl radical formation initiating radical reactions with any hydrogen-donating substance. The progression of lipid peroxidation determines the formation of secondary reactions products, overall leading to the formation of fatty acid peroxides, aldehydes, alcohols, isoprostanes and neuroprostanes [40].

Although beneficial anti-platelet effects [40] [41], it was proposed that a high intake of fish oil could increase bleeding time [42] [43] [44] [45] [46]. Thus, is needed special attention in patients with anticoagulant drugs therapy [47] [48] [49].

PUFAs affects glucose regulation in obese individuals, probably enhancing hepatic gluconeogenesis, an increase in fasting glucose and HbAlc after intake of fish or fish oil, was observed in a few studies [48] [50].

The high presence of food pollutants as Dioxins, Methyl-mercury, Biphenyls, determines adverse effects on Cardio Arterial Diseases (CAD) [51] [52], counteracting cardiovascular benefits of EPA and DHA in accordance on environmental levels. Diets, based, in contaminated fishes, lead to reduction of the cardio-protective effects of n-3 PUFAs versus myocardial infarction due to the presence of methyl mercury [52] [53] or polychlorinated biphenyls [54].

Regarding patients with chronic heart failure of NYHA class II-IV, the administration of $1 \mathrm{~g} \mathrm{n}$-3 PUFA determines gastrointestinal adverse effect of minor clinical relevance [55].

\subsection{Pros and Cons of Statins in COVID-19 Disease}

Statins potentially reduce morbidity and mortality due to COVID-19. With the suspension of HMG-CoA-reductase, as showed in Figure 5, they reduce the regulatory increase in ACE receptors and the excess of ATI. Statins therefore reduce 


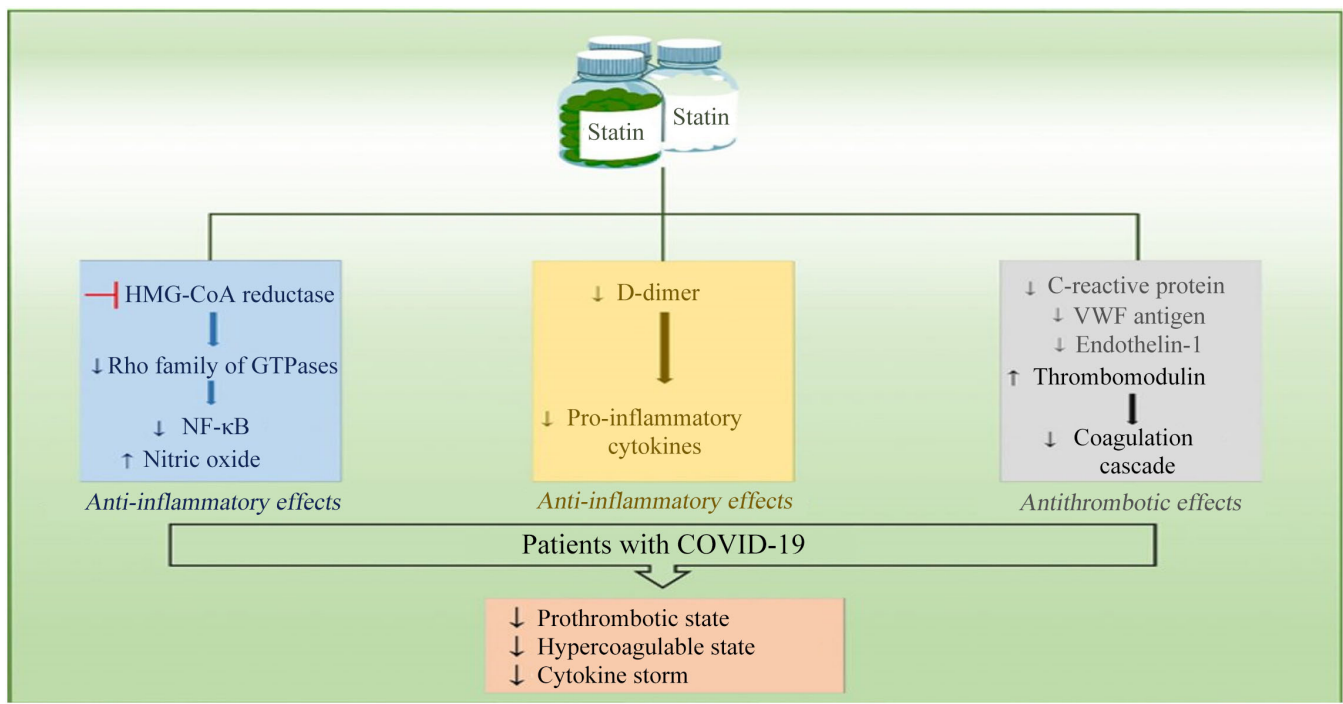

Figure 5. Statins have pleiotropic immunoregulatory anti-inflammatory, antithrombotic and antioxidant effect. Some proposed mechanisms for statins to reduce pro-inflammatory and prothrombotic state in patients with COVID-19. HMG-CoA reductase: 3-hydroxy-3-methylglutaryl-CoA reductase; NF- $\kappa$ B: nuclear factor kappa B; VWF: von Willebrand factor. Ferrari, F., Santos, R. (2021) Statins and COVID-19: To suspend or not to suspend? That is the Question. Arq Bras Cardiol, 116, 1, 147-152.

the damage to the pulmonary parenchyma by increasing ATI. They break down lipid rafts that contribute to the incorporation and endocytosis of the virus and that support ACE2 and reduce the connection of viruses to ACE2, thus blocking the entry of viruses into cells and reducing infectious load [56]. In addition to lowering pro-atherogenic lipoproteins, statins have other well-documented systemic effects, such as improvement in endothelial dysfunction, as well as anti-inflammatory and anti-thrombotic properties that lead to stabilization of atherosclerotic plaques (Figure 5). Meta-analyses of randomized trials have shown that statins can significantly reduce concentrations of C-reactive protein levels of von Willebrand factor antigen, and endothelin-1 concentrations [57] [58] [59] [60].

Statins influenced Immunomodulation. Toll-like receptors (TLR) recognize pathogen-associated molecular patterns on viruses and other pathogens, and together with a set of adapter proteins, activate a signaling cascade that activates nuclear factor-kappa B (NF-kB) to trigger innate immunity. Myeloid differentiation primary response 88 (MyD88) is the main adapter protein for the majority of TLRs [61]. Statins are known TLR-MyD88 pathway antagonists. They stabilize MyD88 levels during hypoxia and stress, thereby mitigating NF-kB activation [62] [63]. The effect of SARS-CoV2 on TLR-Myd88 pathway is largely unknown. However, extrapolating findings from studies with SARS-CoV, it is postulated that effect of statins on MYD88 gene expression might prevent SARS-CoV2 induced lung injury [64]. Interestingly, despite the many limitations of an observational study, Spigeleer et al. reported that statin intake among 153 elderly people with COVID-19 was significantly associated with absence of symptoms; the effect on long-stay hospitalization or death was positive but did not reach statistic- 
al significance (OR 0.75; CI 0.25e1.85) [65].

Regarding Inflammation and oxidative stress, Statins inhibit HMG-CoA reductase, which blocks the generation of mevalonate, the rate-limiting step in cholesterol synthesis. This results in the lowering of low-density lipoprotein (LDL) cholesterol, which in itself has an anti-inflammatory effect as LDL cholesterol is a strong promoter of inflammation [66]. Moreover, mevalonate is also a precursor of many isoprenoid compounds. Hence statins lead to a depletion of farnesyl pyrophosphate and geranylgeranyl pyrophosphate. This inhibition of prenylation of a variety of important cell-signaling small G-proteins leads to down-regulation of NF-kB, suppression of cytokines and chemokines, with resultant anti-inflammatory effect [67]. Statins reduce the serum concentration of the systemic inflammatory bio-marker C-reactive protein (CRP). The evidence for benefit from these anti-inflammatory effects of statins was first realized in people with CVD. In the prospective Pravastatin inflammation/CRP evaluation (PRINCE RCT Study), Pravastatin significantly reduced serum CRP levels at 12 and 24 weeks in subjects with or without CVD, largely independent of changes in LDL cholesterol levels [68]. Similarly, in the landmark JUPITER trial, Rosuvastatin significantly reduced major cardiovascular events in healthy persons with LDLC [69].

In COVID-19 often occur D-dimer levels elevated and abnormal coagulation parameters. These findings are associated with poor prognosis; in people with COVID 19, are common venous and arterial thrombotic events, reported among $31 \%$ of people, in one study referring [70]. Statins have anti-platelet effects; they reduce platelet activation via both lipid lowering and lipid-independent mechanisms [70]. Moreover, statins also have weak anti-thrombotic activity, which is mediated by a complex mechanism. Statins decrease tissue factor protein/activity, which converts factor $\mathrm{X}$ to factor $\mathrm{Xa}$, and tissue plasminogen activator inhibitor-1, and increases the levels of tissue factor pathway inhibitor, thrombomodulin, activated protein C, and tissue plasminogen activator [71].

What about Statins and Lipid Rafts. SARS-CoV2 is an enveloped RNA virus. The S-protein in the viral membrane attacks to the angiotensin-converting enzyme 2 (ACE2) on the host cell membrane, followed by endocytosis of the virus. Membrane/lipid rafts (MLR) are cholesterol-rich areas of the plasma membrane that are important for membrane fusion and endocytosis. Glende et al., in an in-vitro study, showed that a substantial portion of ACE2 is associated with MLR, and a depletion of cholesterol from plasma membrane may disrupt these rafts resulting in reduced viral entry and infectivity. Statin-induced reduction in the percentage of cholesterol in the plasma membrane might alter the assembly of ACE2 receptors, resulting in failure of internalization of the virus [72].

Interestingly, a veil of mystery covers the intricate and complex relationship of statins with the ACE receptors. Statins reduces viral entry in to the cell by altering the assembly of ACE2 by disrupting MLR, but on the other hand they have been shown in animal studies to upregulate the expression of ACE2 [73], with the potential for increasing viral entry into cells. However, the primary role of 
ACE2 is to degrade angiotensin II (Ang-II) to angiotensin 1-7 [Ang-(1e7)]. Ang-II promotes vasoconstriction, oxidative stress and inflammation, whereas Ang-(1e7) opposes these actions of Ang-II. SARS-CoV2 infection causes internalization of ACE2, resulting in a decrease in ACE2 at the cell surface, which leads to excess Ang-II action causing inflammation, tissue damage, fibrosis and loss of pulmonary function [25]. Like angiotensin receptor blockers statins might reduce lung injury induced by excess Ang-II in people with COVID-19 [74].

About statins and impact to viral pneumonias, there is low to moderate quality evidence, that statin use might decrease the severity of, and mortality from, viral pneumonias, possibly due to its immunomodulatory and anti-inflammatory effects [75].

Nevertheless, we have to evaluate and interpret some data against the use of statin during infections and identify potential hazards. In the immediate Table 1 , the pros and cons of statins in COVID-19 disease are collectively illustrated. Serum total, HDL, and LDL cholesterol levels were significantly lower among 71 people hospitalized for COVID-19 when compared to 80 matched healthy controls [76]. Ravnskov has suggested that low serum LDL cholesterol predisposes to infections because LDL particles adhere to and inactivate microorganisms and their toxins [77]. The inverse association between serum cholesterol and morbidity and mortality from infectious diseases was separately noted in a meta-analysis of 19 cohort studies including almost 70,000 deaths [78].

Muscle symptoms/toxicity, and liver dysfunction, are the two prominent, rare, adverse effects of statin therapy often during the first month of therapy. Myalgia presented in $2 \%-7 \%$ of patients with statins [79], while headache, nausea, libido, rash, are presented in $10 \%$ and increased transaminases are presented in $0.2 \%-2.4 \%$ and severe Myopathy in $0.1 \%$ of the people treated with statins us indicated in Figure 6 [80]. People with severe COVID-19 might have skeletal muscle involvement with elevated serum creatine phosphokinase, reported in $19.3 \%$ of such patients in one series or frank rhabdomyolysis; it is essential to discontinue statins in people with COVID-19 with skeletal muscle symptoms [81]. Use of protease inhibitors like Lopinavir/Ritonavir in COVID-19, which are potent inhibitors of cytochrome $\mathrm{P}-450$ system of enzymes, inhibit the metabolism of most statins, thereby significantly increasing their serum levels, with the potential for increased toxicity [82].

Regarding Statins, 58\% of COVID-19 patients present elevated transaminases levels and these can be two times above the upper limit. However, some studies suggest that statin use has no significant impact on ALT levels in COVID-19 patients. It is still unclear whether this elevation is a direct effect of the virus or an indirect systemic inflammatory effect and indeed whether the increase is clinically significant. Nevertheless, liver function should be monitored in patients, especially those using Remdesivir, which causes a significant increase in transaminases and bilirubin levels and can lead to hepatic-cellular damage [83].

Another common side effect of statins is altered carbohydrate metabolism and an increased risk of diabetes (odds ratio 1.09; 95\% CI 1.02-1.17). A me- 
ta-analysis of 91,140 patients found that 255 must take a statin for at least four years to cause one additional episode of diabetes. This effect may be stronger in SARS-CoV-2 patients, as systemic COVID-19 inflammation is associated with deterioration of glycaemia control. Potent glucocorticoid therapy is also a risk factor for glycaemic disorders.

Table 1. Pros and Cons of Statins in COVID-19 disease). Subir, R., Jagat, J.M., Kalyan, K.J., 2020 [12].

\begin{tabular}{|c|c|c|}
\hline \multicolumn{3}{|l|}{ PROS } \\
\hline AREA OF INTEREST & Action of statins & CLINICAL EFFECTS IN PATIENTS COVID-19 \\
\hline $\begin{array}{l}\text { Inflammation } \\
{[13][14]}\end{array}$ & $\begin{array}{l}\text { 1) Reduction of LDL cholesterol levels, thereby reducing direct } \\
\text { LDL cholesterol mediated inflammation } \\
\text { 2) Inhibition of prenylation of G proteins, leading to } \\
\text { down-regulation of NF-kB, suppression of pro-inflammatory } \\
\text { cytokines (TNF a, IL-6) and chemokines (IL-8) }\end{array}$ & $\begin{array}{l}\text { Potential role in reduction of SARS-CoV2 induced lung } \\
\text { injury and protection from cytokine storm }\end{array}$ \\
\hline $\begin{array}{l}\text { Oxidative Stress } \\
{[18]}\end{array}$ & $\begin{array}{l}\text { Reduction of oxidative injury/maintenance of the redox balance } \\
\text { of the endothelium by: } \\
\text { 1) Upregulation of nitric oxide syntliase } \\
\text { 2) Suppression of pro-oxidant enzymes (NADPH oxidase) }\end{array}$ & $\begin{array}{l}\text { Potential role in reduction of SARS-CoV2 induced } \\
\text { lung injury }\end{array}$ \\
\hline \multirow{3}{*}{ Thrombosis [21] [22] } & $\begin{array}{l}\text { 1. Anti-platelet effect (Lipid dependent and lipid independent } \\
\text { mechanisms) }\end{array}$ & \\
\hline & $\begin{array}{l}\text { 2. Weak anti-thrombotic effect } \\
\text { 1) Prevents the conversion of factor } \mathrm{X} \text { to } \mathrm{Xa} \text { by down regulating } \\
\text { tissue factor }\end{array}$ & $\begin{array}{l}\text { Potential to reduce/prevent venous and arterial } \\
\text { thrombus formation }\end{array}$ \\
\hline & 2) Uoregulation of thrombomodulin to bind thrombin & \\
\hline $\begin{array}{l}\text { Membrane (lipid) rafts } \\
\text { [23] }\end{array}$ & $\begin{array}{l}\text { Disruption of lipid rafts by depletion of cholesterol from the } \\
\text { plasma membrane, which might alter the assembly of } \\
\text { angiotensin converting enzyme } 2 \text { receptors (act as co-receptors } \\
\text { for SARS-CoV2 entry into the cell) }\end{array}$ & $\begin{array}{l}\text { Theoretical possibility ofreducing viral entry, leading to } \\
\text { low viral titres and infectivity }\end{array}$ \\
\hline (ACE2) [4] [24] & Upregulation of expression of ACE2 & $\begin{array}{l}\text { Potential to reduce SARS-CoV2 induced lung injury } \\
\text { mediated by excess Angiotensin- } 11\end{array}$ \\
\hline \multicolumn{3}{|l|}{ CONS } \\
\hline $\begin{array}{l}\text { Tot cholesterol/ LDL } \\
\text { cholesterol levels [7] }\end{array}$ & Reduction of serum total and LDL cholesterol & $\begin{array}{l}\text { Speculated that this might increase morbidity/mortality } \\
\text { from SARS-CoV2 infection, as elevated illL cholesterol is } \\
\text { protective since illL particles adhere to and inactivate } \\
\text { microorganisms and their toxins }\end{array}$ \\
\hline $\begin{array}{l}\text { Immunomodul ation } \\
{[10]}\end{array}$ & Inhibition of MyD88 expression & $\begin{array}{l}\text { Speculated to reduce innate immunity response, } \\
\text { thereby worsening infection }\end{array}$ \\
\hline $\begin{array}{l}\text { Angiotensin converting } \\
\text { enzyme } 2 \text { (ACE2) [24] }\end{array}$ & Upregulation of expression of ACE2 & Potential to increase SARS-CoV2 entry into cells \\
\hline $\begin{array}{l}\text { Myositis and liver } \\
\text { dysfunction [31] [32] } \\
{[33][34]}\end{array}$ & $\begin{array}{l}\text { I. Mild elevation of liver enzymes in } 10 \% \text {, and elevation }>3 \text { times } \\
\text { upper limit of normal in } 1 \%-3 \% 2 \text {. Myalgia in } 2 \%-7 \%\end{array}$ & $\begin{array}{l}\text { Detrimental effect in people with COVID-19 with } \\
\text { skeletal muscle symptoms or liver dysfunction }\end{array}$ \\
\hline $\begin{array}{l}\text { Drug interactions [35] } \\
\text { [37] }\end{array}$ & $\begin{array}{l}\text { Inhibition of cytochrome P- } 450 \text { group of enzymes by protease } \\
\text { inhibitors used in COVID-19 may significantly increase statin } \\
\text { levels }\end{array}$ & Increased risk of toxicity: myopathy and rhabdomyolysis \\
\hline
\end{tabular}




$\begin{array}{lll}\text { Adverse effect } & \text { Incidence } & \text { Comment } \\ \begin{array}{l}\text { Headache, nausea } \\ \text { rash, decreased libido }\end{array} & 10 \% & \text { Not dose -related } \\ \text { Increased transaminases } & 0.2-2.4 \% & \text { Dose-related } \\ \text { Myopathy } & 0.1 \% & \text { Dose-related } \\ \text { Rhabdomyolysis } & 0.0002 \% & \text { Dose-related }\end{array}$

Figure 6. Incidence of adverse effects of statins. Wilson, W. Thomas, (2005) Management of the Statin, Intolerant Patient Current. Perspectives in Cardiology, 27, 26-28.

The CORONADO study found routine statin treatment before hospitalization was significantly associated with increased seven-day $(12.8 \%$ vs. $9.8 \%$, respectively; $\mathrm{p}=0.02)$ and 28 -day $(23.9 \%$ vs. $18.2 \%$, respectively; $\mathrm{p}<0.001)$ mortality in 2449 type 2 diabetes mellitus (T2DM) patients hospitalized for COVID-19 [83].

However, other studies do not confirm these results. A study of 4252 COVID-19 patients, including 2266 with type 2 diabetes, found statin treatment to be associated with lower serum CRP levels (10.2; interquartile range (4.5-18.4) versus 12.9; interquartile range $(5.9-21.4) \mathrm{mg} / \mathrm{dL} ; \mathrm{p}<0.01)$ and reduced cumulative in-hospital mortality ( $24 \%$ versus $39 \%$; $<0.01)$ [83].

According to HEART UK experts, atorvastatin cannot be co-administered with Remdesivir and should be modified to Rosuvastatin. Tocilizumab is forbidden to combine with any statin and in such case statin therapy should be temporarily suspended. Dexamethasone is compatible to statin therapy. Thus, any decision to administer a statin must be considered on an individual basis, considering the risks and benefits for each patient [83].

Figure 6 shows the aggregate percentage of adverse effects incidence of statins and identifies which of side effects, is dose-dependent or no. Then, Table 6 is very important and crucial, as they are exhibited collectively pros and cons of statins in COVID-19 disease, the statin actions in various areas of interest, the impact of statins on the various physiopathological mechanisms, activated during COVID-19 disease and the clinical effects they produce in COVID-19 patients.

\section{Results}

With reference to the treatment option of administering bioactive lipids on their own or in combinations with other medicines such as HDL, ASA, mesenchymal stem cells, antioxidant vitamins C and D, NSAIDs, DPP4 inhibitors, statins, GLP-1, colchicine etc. potentially offer benefits in the treatment of COVID-19, but we do not still know their effectiveness and other randomized studies are needed. The administration of exogenous $D$ and E Resolvins is effective in critical COVID-19, since they have increased bioavailability and rapid biological activity. Preparations with Apo-A1 growth factors as well as preparations with LCAT (lecithin-cholesterol-acyltransferase) improve the function of HDL [6] [11]. 
Purpose of administration of exogenous bioactive lipid (BALs) supplements and in particular SPMs, is the suppression of pro-inflammatory cytokines, IL-6, TNF-a, IFN-c and the prevention of cytokine storm that promotes SARS-COV-2, the strengthening of the solution of inflammation, the antithrombotic, anti-platelet action, the potentially anti-viral properties of reducing oxidative stress and enhancing the therapeutic benefit by accelerating recovery [84] [85].

Supplementation of omega-3 has also been studied in the setting of ARDS and was used earlier in ARDS. It has been observed that the enteral administration of fish oil (rich in antioxidants and w-3 PUFAs) can enhance oxygenation and clinical benefits in the patients of the intensive care unit (ICU) [86]. In a study by Li et al. [87] suggested a favorable effect merely for patients with ARDS, after conducting a systematic review in 2015. Pontes-Arruda et al. reported significant reduction, in ventilator-free days, organ failure and length of stay in ICU and mortality in ARDS COVID-19 patients. Additionally a Cochrane Review, a Metanalysis emphasized the significance of clinical trials to elucidate the use of antioxidants and w-3 fatty acids in patients suffering from ARDS, shows that the somministration of EPA-DHA in ARDS patients of COVID-19 disease improve significantly in blood oxygenation, reduction of ventilation demands, the total number of days passed on ventilators and the length of stay in ICU [88] [89]. In a study done in 2015, it was determined that natural antioxidants like omega-3 only lead to a statistically significant decrease in mortality in those suffering from ARDS [36].

EPA rich fish oil, administered exogenously in combination with g-linoleic acid and antioxidants such as vitamins $C$ and $D$ improve the clinical outcome of the disease in a multifactorial way: Increase SPMs anti-inflammatory derivatives in circulation and through heterocytosis enhance phagocytosis and elimination of apolytic cells. They promote recovery from severe COVID-19 disease and reduce mortality [90] [91].

The combination of AA (Arachidonic Acid) and SPMs is considered safe and the LXA4 formation is strengthened, while we have little or no change in PGE2. The combination of omega- 3 fats and aspirin, an anti-COX 1, 2 substances with anti-platelet properties, in addition to reducing pro-inflammatory metabolites of eicosanoids, enhances the action of EPA/DHA [10] [91].

OEA (OleoYlethanolamid Acid), a bioactive lipid amide with distinct homeostatic properties derived from Omega-9 Oleic acid and interacting with the PPAR-a receptor, reduces inflammatory cytokine IL-6 and IL1B, prevents gene expression for the production of pro-inflammatory cytokines, and reduces endothelial damage and the oxidative stress [92].

Infusions of Mesenchymal Stem Cells (MSCs), through their ability to secrete bioactive lipids (BALs), provide significant benefit to COVID-19 morbidity, ICI therapy and Sepsis [93].

Though the effect of w-3 administration in ARDS has to be better elucidated, however, it plays a crucial role in decreasing reactive oxygen species and proin- 
flammatory cytokines, including IL-6, IL-8, IL-1b, and TNF-a Therefore, w-3 may be considered as one of the potential antiviral treatments for COVID-19 [94].

Regarding statins, it is already know, they have pleiotropic immunoregulatory anti-inflammatory, antithrombotic and antioxidant effects, therefore potentially reduce morbidity and mortality. With the suspension of HMG-CoA-reductase, they reduce the regulatory increase in ACE receptors and the excess of ATI. Statins therefore reduce the damage to the pulmonary parenchyma by increasing ATI. They break down lipid rafts that contribute to the incorporation and endocytosis of the virus and that support ACE2 and reduce the connection of viruses to ACE2, thus blocking the entry of viruses into cells and reducing infectious load [56].

Statins according to the international literature (Alijotas - Reig et al., 2020; Rizk et al., 2020) potentially benefit patients with COVID-19 hyper inflammatory reaction, due to their anti-inflammatory properties which include the reduction of proinflammatory cytokines, in combination with their conventional cardio protective actions [95].

Also according to a Retrospective Cohort Study in Wuhan (Zhang, Qin, Cheng, et al., 2020), the use of Atorvastatin and Rosuvastatin in COVID-19 patients reduced overall mortality as a primary endpoint $(\mathrm{HR}=0.63, \mathrm{CI} 0.48$ $0.84)$. Better prognosis and reduced mortality were associated with immunoregulatory and anti-inflammatory effects of statin [95].

In another retrospective cohort study by Lala, (Lala et al., 2020), it was observed that statin use in patients $(24 \%$ history of CVD, $\mathrm{N}=3069)$ with acute myocardial infarction and elevated Troponin levels as a complication of COVID-19 disease, was associated with improved survival (HR $=0.57,95 \%$ CI 0.47 - 0.69) [95].

The action, especially of lipophilic statins, as long as they are distributed and accumulated in the tissues of target organs affected by the virus, is beneficial as they significantly reduce mortality from COVID-19. There is scientific evidence that moderate to high doses of statins may be effective in the disease but we have not scientifically identified a more appropriate, safer and more effective dosage of statins [96].

The potential adverse effects of statins, in severe COVID-19 disease are significant. They regulate the expression and the activity of ACE2 upwards and increase the ATII levels, thus enhancing the entry of viruses into cells, while ACE2 allows the conversion of ATI to ATI 1-7 thus blocking the actions of ATI [12].

Statins causing myositis and liver damage, they interact with drugs metabolized in P450 cytochrome such as Ritonavir and Lopinavir, protease inhibitors and thus statin levels become toxic and there is a risk of rhabdomyolysis and myopathy. Davidson's study (Davidson, et al., 2007), show that some patients, despite taking statins have elevated triglycerides, which places them, due to high residual cardiovascular risk, at high risk for cardiovascular events and severe COVID-19 disease [12]. 
On the advisability of the discontinuing statins during COVID-19 disease, these drugs may reduce the pro-inflammatory and pro-thrombotic mechanisms that characterize more severe cases of COVID-19 [97].

We found dyslipidemia patients had a significant trend towards a higher innate immune response shown by higher white cell counts and neutrophils counts. Statin use was independently associated with lower requirement for ICU admission. This supports current practice to continue prescription of statins in hyperlipidemia and other metabolic disorders in COVID-19 patients [98].

In conclusion, currently, there is no evidence to support discontinuation of statins in patients with COVID-19, except when important elevations of hepatic enzymes, rhabdomyolysis, or drug-attributed risk of life occur. On the other hand, there is no indication for the use of these drugs specifically to prevent complications of SARS-CoV-2 infection [97].

In a retrospective cohort study from Belgium, De Spiegeleer et al. evaluated 154 elderly people (mean age: 86 years) who contracted COVID-19, and observed a significant trend for absence of symptoms in those previously taking statins (OR 2.91; 95\% confidence interval (CI), 1.27 to 6.71). This remained statistically significant even after adjusting for covariates (OR 2.65; 95\% CI, 1.13 to 6.68) [99].

Another retrospective study of approximately 14,000 patients with COVID-19 found a lower risk of mortality with previous use of statins. In this study, 1219 patients were receiving statins, and the all-cause mortality at 28 days in this group was $5.2 \%$, while in the non-statin group it was $9.4 \%$ (adjusted hazard ratio [HR] $0.58 ; 95 \% \mathrm{CI}, 0.43$ to $0.80 ; \mathrm{p}=0.001$ ) [100]. In another study with 87 patients with COVID-19 admitted to the intensive care unit, a slower progression to death was found in those receiving atorvastatin [101].

Daniels et al. [102] through a retrospective single-center study, found a reduced risk of severe COVID-19 in patients who were using statins prior to admission (adjusted OR 0.29), and a faster time to recovery among those without severe disease (HR adjusted for recovery 2.69). In addition, in a retrospective cohort study of patients hospitalized with COVID-19 $(\mathrm{N}=249)$ in the United States, the use of statins correlated with decreased risk for invasive mechanical ventilation (adjusted OR 0.45) [103].

There is some evidence that statins could prevent infections. These results, which deserve to be proven in an adequately designed trial, suggest that statins may reduce pneumonia risk due to possible beneficial mild anti-inflammatory, antioxidant, immunomodulatory, anti-apoptotic, and endothelial effects according to the authors [104].

In a post hoc analysis of patients included in the JUPITER trial, which randomized 17,802 individuals with LDL-C $<130 \mathrm{mg} / \mathrm{dL}$ and high-sensitivity C-reactive protein $\geq 2.0 \mathrm{mg} / \mathrm{L}$ to receive Rosuvastatin $20 \mathrm{mg} /$ day. Observed that the use of statins reduced, modestly, the incidence of pneumonia (HR 0.83, 95\% CI, 0.69 to 1.00$)$ [105]. 
In addition to pulmonary complications, SARS-CoV-2 may also induce thrombosis [106]. In a pre-specified analysis of the same JUPITER trial, although there were no differences in the rates of pulmonary embolism between the groups (Rosuvastatin and placebo), the group that received the statin showed a $43 \%$ reduction in the rates of venous thromboembolism (HR 0.57; 95\% CI, 0.37 to $0.86 ; \mathrm{p}=0.007$ ) [107] [108].

Furthermore, a study-level meta-analysis of 13 observational cohort studies $(\mathrm{N}=3,148,259)$ and 23 randomized clinical trials $(\mathrm{N}=118,464)$ showed that, in both observational cohort studies and randomized clinical trials, there was a reduction in risk of deep venous thromboembolism but not of pulmonary embolism, when statin use was compared with controls (relative risk [RR] 0.75; 95\% CI, 0.65 to $0.87 ; \mathrm{p}<0.0001 ; 0.85 ; 95 \%$ CI, 0.73 to $0.99 ; \mathrm{p}=0.038$ ) [109]. Possible mechanisms to explain these results include the effects of statins on pro-thrombotic factors, such as reduced D-dimer, factor VIII, plasminogen activator inhibitor 1, and tissue factor levels, as well as decreased platelet aggregation and increased expression of thrombomodulin [110] [111].

\section{Conclusions}

In our review we critically examined, in combination, the potentially benefits and the possible harms of omega-3 supplementations as co-therapy for patients infected with SARS-CoV-2, as well as the benefits and the possible adverse effects of statins in COVID-19 disease. We must take in to account two indisputable parameters: first, although the potential benefits of omega- 3 fatty acids in COVID-19 are based on well documented experimental trials, the risk of high doses of lipids supplementation in severe SARS-CoV-2 infection must be further researched. Second, some points about the virus pathology are still undiscovered and other characteristics or comorbidities of the patients which are involved in their recovery are still unknown [95].

Additionally, following the original OMEGA survey published in JAMA (Rice, Wheeler et al. JAMA, 2011) the usefulness of $\mathrm{n}-3$ fatty acids, $\gamma$-linolenic acid and antioxidants in the critically ill, in sepsis, systemic inflammatory response, and acute lung injury (ALI) is still controversial. PUFAs produce excess of proinflammatory cytokines and eicosanoids with poor outcome for critical ill patients, while simultaneously they secrete anti-inflammatory products with favorable clinical outcome. Hence, is a critical need the measurement of plasma cytokines level, free radicals and pro-anti inflammatory PUFAs, to combine them with clinical evolution and identified prognostic markers and safe therapies [110].

Omega- 3 fatty acids, due to their already note anti-inflammatory action, could ameliorate some patients need for intensive care unit (ICU) admission. From the present review, it was found that EPA and DHA while benefiting patients and contributing to the reduction of morbidity from COVID-19 and improve their recovery, by weakening the mechanisms of action of viruses, namely, cytokines storm, oxidative stress they seem to significantly reduce cardiovascular compli- 
cations and promote the resolution of systemic inflammation. However supplements Omega-3 do not constitute yet, a scientific evidence based recommendation, as other parameters of treatment need to be clarified so further research is needed [95].

Statins offer significant benefits due to their note pleiotropic and anti-inflammatory properties for COVID-19-associated cardiovascular complications, reduced overall mortality, improved the prognosis and improved survival of severe COVID-19 disease, but we must take into account the potential side effects [95].

Also the prospect of co-administration of bioactive lipids that succeed in lowering TG in patients already taking statins with high TG is an interesting and promising option in further reducing the risk of cardiovascular events in severe COVID-19 disease [95].

Ultimately there is a debate to suspend or no Statins during COVID-19. European Society of Cardiology guidelines, suggested suspending temporary statins in rare cases where patients with COVID-19 develop severe rhabdomyolysis or increased liver enzymes [111]. Additionally, suspension should be performed, at least until recovery from the infection, if the patient is at crucial risk of life [112].

The consideration that low cholesterol is detrimental to patients with COVID-19 may lead to unsuitable suspension of statins, in patients at high risk of cardiovascular diseases. It's already noted that statins reduce the risk of Coronary Artery Disease (CAD). A Metanalysis showed that for each $1.0 \mathrm{mmol} / \mathrm{L}$ $(\sim 40 \mathrm{mg} / \mathrm{dL})$ reduction of LDL-C, all-cause mortality was reduced by $10 \%$ (RR $0.90,95 \% \mathrm{CI}, 0.87$ to $0.93 ; \mathrm{p}<0.0001)$, in addition to a $20 \%$ reduction in CAD deaths (RR 0.80; 99\% CI, 0.74 to 0.87 ; $<<0.0001$ ) [113].

In an analysis of patients presenting with CAD, during PRISM Study, Heeschen et al., reported that the use of statins reduced the rate of events after 30 days, compared to patients without those medications (adjusted HR 0.49, 95\% CI, 0.21 to 0.86 ). When statins were suspended after admission, cardiac risk increased (OR 2.93; 95\% CI, 1.64 to 6.27 ; $\mathrm{p}=0.005$ ), and, although it was not statistically significant, there was a trend to greater risk compared to patients who had never received statins (OR 1.69; 95\% CI, 0.92 to 3.56) [114] [115].

In a Metanalysis of Kow et al. (Kow et al. 2020), was revealed a significantly reduced hazard for fatal or severe disease with the use of statins (pooled HR = 0.70; 95\% CI 0.53 - 0.94) compared to non use of statins in COVID-19 patients. Preliminary findings suggested a reduction in fatal or severe disease by $30 \%$ and discredited the suggestion of harms with the use of statins in COVID-19 patients. Available evidence suggests that statin therapy of moderate-to-high intensity could be effective [116].

It is noteworthy that the following questions arise about statins. An advantage for statin treatment is protection against potential coronary endothelial dysfunction caused by SARS-CoV-2. If statins increase ACE-2, can they be a risk factor for SARS-CoV-2 infection? But what are the real effects of statins on ACE-2? If statins are used with ACEi or ARB therapy, can there be an additional effect on 
the modulation of ACE-2? And what clinical effects can there be? In conclusion, to date it is not clear how the clinical results in patients with COVID-19 are affected by the use of statins, alone or in combination with ACEi and ARB [117].

The withdrawal of statins should be viewed with extreme caution, especially after an acute coronary event, since this may lead to appearance of complications, worsening patients' prognosis. Currently, there is no evidence to support discontinuation of statins in patients with COVID-19, except when important elevations of hepatic enzymes, rhabdomyolysis, or drug-attributed risk of life occur [97].

\section{Discussion}

\subsection{Summary}

Bioactive lipids and statins have potentially beneficial effects in the treatment of COVID-19 disease. However, the physiopathological characteristics of the disease as well as the parameters concerning the drugs themselves need to be clarified and Randomized Controlled Studies should be carried out in order to have further scientific evidence for their safety.

\subsection{Strenghts and Limitations}

Inclusion and exclusion criteria have been reported, multiple data bases were searched, the objective and purpose of the study was clearly stated, study selection was prescribed, and list of included studies was provided. We strive to avoid selection bias, referencing of only information that supports our conclusions, since we focused some controversies that demand more research to clarify completely the safeness and the real benefit of the COVID19 disease treatment with lipids, take to the account the possible harms.

Our predetermined criteria, were, us including criteria, the established key words and secondly we selected various studies that include not only potential benefits of bioactive lipids or statins in the serious COVID-19 disease but also potential harms and side effects as a result of their use, in order to reduce publication bias and second, us excluding criteria of studies, were mainly based to how recent were the studies and their obligation to indicate the combination of lipids with COVID-19.

Articles selected by databases of evidence based reviews, regarding this topic, were mainly, Cohort studies, Reviews, Letters to editor, and the referring information that has been yielded was level B strength of evidence. This is a non randomized control study, therefore our findings has a low grade evidence related to RCT information level of evidence, so it's impossible to fulfill the knowledge gap regarding the question, but our intention was to contribute and supplement the current knowledge.

Additionally, we don't provide any mathematical analytic model to answer a focus clinical question, using rigorous statistical analysis to adjust for bias, so our data do not meet the reliability and accuracy afforded by the methodological 
rigor of RCTs and do not provide a reliable way of comparing treatment strategies.

\subsection{Implications for Research/Practise}

The findings of our review confirm the results of the existing literature, where bioactive lipids and statins potentially alleviate the severity of COVID-19 disease. We try to approach the issue of the treatment of severe covid-19 disease more holistically and to highlight the benefits of both treatments in combination with other drugs or alone.

It was also pointed out that the combination of lipids in patients with high triglycerides already receiving statins could further reduce the residual cardiovascular risk of COVID-19 cardiovascular complications, prompting an attempt by the pharmaceutical industry to produce combinations of lipids and other substances and a combination of lipid and statin supplements.

Regarding the practical consequences, it should be emphasized that this study is only a minimal contribution to the investigation of the issue of COVID-19 treatment, but it cannot be considered as a model for inclusion of its findings in guidelines in the daily practice of its treatment.

\subsection{Comparison with Existing Literature}

The international literature provides clinical evidence on the beneficial pleiotropic, anti-inflammatory and immunomodulatory effects of bioactive lipids against viral or bacterial invasion, as well as the reduction of Acute Lung Injury (ALI), SARS, Sepsis and duration of ICU stay, while bioactive lipids reduced mortality rates and improved clinical and laboratory outcomes. In our review, we critically review the possibility of PUFA and the Statins being incorporated as routine treatment into the protocols for severe COVID-19 disease and examine whether the benefit of bioactive lipids and statins is greater and more significant than the potential harm they may cause.

An Albert and colleagues' study, demonstrated that diets rich in fish, containing high levels of produces a statistically significant reduction in mortality rates from cardiovascular facts. Diets rich in Omega-3's can reduce the risk of death, by half, for men from the cardiovascular event. Also they potentially reduce the need for ICU hospitalization and the number of intensive care days of staying and recovery, thus also numerically reducing critical cases [11] [26].

Similar clinical information suggests that Statins, due to their pleiotropic, anti-inflammatory effects (including reduction of cytokines), benefit the hyper inflammatory response to COVID-19, in addition to their conventional cardioprotective properties (Alijotas, Reig, et al., 2020; Rizk, et al., 2020), and improve the secondary risk for cardiovascular events in patients at high cardiovascular risk such as diabetics, obese, patients with acute coronary syndromes, which are also risk factors for severe COVID-19 disease (Stone, et al., 2013) [95].

Retrospective studies have also shown that the use of statins in hospital pa- 
tients with COVID-19 improves mortality rates and prognosis in hospital patients (Zhang, Qin et al., 2020). Statins also appear to be beneficial in hospital patients with COVID-19, as they reduce the mortality rate compared to non statin users and improved prognosis associated with in hospital statin use in addition to their typical pleiotropic cardioprotective actions. Nevertheless, statins are also reported in the literature as having the potential to further potentiate COVID-19 disease, as they enhance the expression and activity of ACE-2 receptors, thus increasing the production and activity of ATII [95].

In relation to other studies, our study confirms the results of previous studies and adds a wider and expanding critical view for the usefulness and effectiveness of not only bioactive lipids but also statins incorporated both in a unique article, further enriching the current knowledge of the severe COVID-19 disease therapy.

\section{Author Contributions}

All authors have read and approved the manuscript and contribute equally.

\section{Funding Support}

Authors declare none. This research did not receive any specific grant from funding agencies in the public, commercial, or not-for-profit sectors.

\section{Acknowledgements}

This review is intended to assist the scientific community in its efforts to address the awesome, invisible enemy of the entire humanity, SARS-COV2. We express our sincere, cordial recognition, respect, admiration and gratitude to the dedication, abnegation and sacrifice of all the health stuff, scientists, pharmacists and pharmaceutical companies, security forces, public service workers, global health decision making bodies, governments and all the various frontline workers at this challenging, crucial moments of the global community.

\section{Compliance with Ethical Standards}

\section{Ethical Approval}

Authors declare no violation of ethical standards.

\section{Informed Consent}

For this type of article, formal consent does not apply.

\section{Conflicts of Interest}

The authors declare no conflicts of interest regarding the publication of this paper.

\section{References}

[1] Tedros, A.G. (2020) WHO Director-General's Opening Remarks at the Media 
Briefing on COVID-19.

[2] Guo, Y.-R., Cao, Q.-D., Hong, Z.-S., Tan, Y.-Y., Chen, S.-D., Jin, H.-J., et al. (2020) The Origin, Transmission and Clinical Therapies on Coronavirus Disease (COVID-19) Outbreak-An Update on the Status. Military Medical Research, 7, Article No. 11 https://doi.org/10.1186/s40779-020-00240-0

[3] Subbarao, K. and Mahanty, S. (2020) Respiratory Virus Infections: Understanding COVID-19. Immunity, 52, 905-909. https://doi.org/10.1016/j.immuni.2020.05.004

[4] Sungnak, W., Huang, N., Bécavin, C., Berg, M. and HCA Lung Biological Network (2020) SARS-CoV-2 Entry Genes Are Most Highly Expressed in Nasal Goblet and Ciliated Cells within Human Airways. http://arxiv.org/abs/2003.06122

[5] Hossain, F., Hasana, Sh., Mamun, A.A., Uddin, M.S., Wahed, M.I.I., Sarker, S., et al. (2020) COVID-19 Outbreak: Pathogenesis, Current Therapies, and Potentials for Future Management. Frontiers in Pharmacology, 11, Article No. 563478. https://doi.org/10.3389/fphar.2020.563478

[6] Sorokin, A., Karathanasis, S., Yang, Z.H., Freeman, L., Kotani, K. and Remaley, A.T. (2020) COVID 19 Associated Dyslipidemia: Implications for Mechanism of Impaired Resolution and Novel Therapeutic Approaches. FASEB J, 34, 9843-9853. https://doi.org/10.1096/fj.202001451

[7] Undarti, D.N. (2020) Can Bioactive Lipids Inactivate Coronavirus (COVID-19)? Archives of Medical Research, 51, 282-286. https://doi.org/10.1016/j.arcmed.2020.03.004

[8] Undarti D.N. (2020) Response to Bioactive Lipids and Coronavirus/Further discussion. Archives of Medical Research, 51, 445-449. https://doi.org/10.1016/j.arcmed.2020.04.004

[9] Undarti, D.N. (2011) Bioactive Lipids in Atherosclerosis, Review. Hellenic Journal of Nutrition and Dietetics, 2, 11-18.

[10] Undarti, D.N. (2020) Can Bioactive Lipid Ameliorate Acid Prevent and Ameliorate COVID 19. Medicina, 56, Article No. 418. https://doi.org/10.3390/medicina56090418

[11] Rogero, M., Leao, M., Santana, T., Pimentel, M., Carlini, G., da Silveira, T., et al. (2020) Potential Benefits and Risks of Omega-3 Fatty Acids Supplementation to Patients with COVID-19. Free Radical Biology and Medicine, 156, 190-199. https://doi.org/10.1016/j.freeradbiomed.2020.07.005

[12] Subir, R., Jagat, J.M. and Kalyan, K.J. (2020) Pros and Cons for Use of Statins in People with Coronavirus Disease-19. Diabetes \& Metabolic Syndrome: Clinical Research \& Reviews, 14, 1225-1229. https://doi.org/10.1016/j.dsx.2020.07.011

[13] McClaskey, E.M. and Michalets, E.L. (2007) Subdural Hematoma after a Fall in Elderly Patient Taking High-Dose Omega-3 Fatty Acids with Warfarin and Aspirin: Case Report and Review of the Literature. Pharmacotherapy, 27, 152-160. https://doi.org/10.1592/phco.27.1.152

[14] Gutierrez, S., Svahn S.L. and Johansson, M.E. (2019) Effects of Omega-3 Fatty Acids on Immune Cells. International Journal of Molecular Sciences, 20, Article No. 5028. https://doi.org/10.3390/ijms20205028

[15] Parolini, C. (2019) Effects of Fish n-3 PUFAs on Intestinal Microbiota and Immune System. Marine Drugs, 17, Article No. 374. https://doi.org/10.3390/md17060374

[16] Radzikowska, U., Rinaldi, A.O., Celebi, S., Wojcik, M., Karaguzel, D., Wojcik, M., et al. (2019) The Influence of Dietary Fatty Acids on Immune Responses. Nutrients, 11, Article No. 2990. https://doi.org/10.3390/nu11122990 
[17] Cai, C., Koch, B., Morikawa, K., Suda, G., Sakamoto, N., Rueschenbaum, S., et al. (2018) Macrophage-Derived Extracellular Vesicles Induce Long-Lasting Immunity against Hepatitis C Virus Which Is Blunted by Polyunsaturated Fatty Acids. Frontiers in Immunology, 9, Article No. 723. https://doi.org/10.3389/fimmu.2018.00723

[18] Sharma, S., Chhibber, S., Mohan, H. and Sharma, S. (2013) Dietary Supplementation with Omega-3 Polyunsaturated Fatty Acids Ameliorates Acute Pneumonia Induced by Klebsiella pneumoniae in BALB/c Mice. Canadian Journal of Microbiology, 59, 503-510. https://doi.org/10.1139/cjm-2012-0521

[19] Calder, P.C. (2013) Omega-3 Polyunsaturated Fatty Acids and Inflammatory Processes: Nutrition or Pharmacology? British Journal of Clinical Pharmacology, 75, 645-662. https://doi.org/10.1111/j.1365-2125.2012.04374.x

[20] Sorensen, L.S., Thorlacius-Ussing, O., Schmidt, E.B., Rasmussen, H.H., Lundbye-Christensen, S., Calder, P.C., et al. (2014). Randomized Clinical Trial of Perioperative Omega-3 Fatty Acid Supplements in Elective Colorectal Cancer Surgery. British Journal of Surgery, 101, 33-42. https://doi.org/10.1002/bjs.9361

[21] Yang, X., Yu, Y., Xu, J., Shu, H., Xia, J., Liu, H., et al. (2020) Clinical Course and Outcomes of Critically Ill Patients with SARS-CoV-2 Pneumonia in Wuhan, China: A Single-Centered, Retrospective, Observational Study. The Lancet Respiratory Medicine, 8, 475-481. https://doi.org/10.1016/S2213-2600(20)30079-5

[22] Begin, M.E. and Das, U.N (1986) A Deficiency in Dietary Gamma-Linolenic and/or Eicosatetraenoic Acids May Determine Individual Susceptibility to AIDS. Medical Hypotheses, 20, 1-8. https://doi.org/10.1016/0306-9877(86)90080-0

[23] Morita, M., Kuba, K., Ichikawa, A., Nakayama, M., Katahira, J., Iwamoto, R., et al. (2013) The Lipid Mediator Protectin D1 Inhibits Influenza Virus Replication and Improves Severe Influenza. Cell, 154, 112-125.

https://doi.org/10.1016/j.cell.2013.02.027

[24] Hathaway, D., Pandav, K., Patel, M., Riva-Moscoso, A., Singh, B.M., Patel, A., et al. (2020) Omega-3 Fatty Acids and Covid-19: A Comprehensive Review. Infection \& Chemotherapy, 52, 478-495. https://doi.org/10.3947/ic.2020.52.4.478

[25] Saifullah, A., Watkins, B.A., Saha, C., Li, Y., Moe, S.M. and Friedman, A.N. (2007) Oral Fish Oil Supplementation Raises Blood Omega-3 Levels and Lowers C-Reactive Protein in Haemodialysis Patients-A Pilot Study. Nephrology Dialysis Transplantation, 22, 3561-3567. https://doi.org/10.1093/ndt/gfm422

[26] Albert, C.M., Hennekens, C.H, O’Donnell C.J., Ajani, U.A., Carey, V.J., Willett, W.C., et al. (1998) Fish Consumption and Risk of Sudden Cardiac Death. JAMA, 279, 23-28. https://doi.org/10.1001/jama.279.1.23

[27] Körner, A., Schlegel, M. and Theurer, J. (2018) Resolution of Inflammation and Sepsis Survival Are Improved by Dietary $\Omega$-3 Fatty Acids. Cell Death \& Differentiation, 25, 421-431. https://doi.org/10.1038/cdd.2017.177

[28] Saedisomeolia, A., Wood, L.G. and Garg, M.L. (2009) Anti-Inflammatory Effects of Long-Chain n-3 PUFA in Rhinovirus-Infected Cultured Airway Epithelial Cells. British Journal of Nutrition, 101, 533-540. https://doi.org/10.1017/S0007114508025798

[29] Sakai, C., Ishida, M., Ohba, H., Yamashita, H., Uchida, H., Yoshizumi, M., et al (2017) Fish Oil Omega-3 Polyunsaturated Fatty Acids Attenuate Oxidative Stress-Induced DNA Damage in Vascular Endothelial Cells. PLOS ONE, 12, e0187934. https://doi.org/10.1371/journal.pone.0187934

[30] Daniells, S. (2010) Omega-3 Shows Benefits against 'Oxidative Stress': Study. https://www.nutraingredients.com/Article/2010/06/23/Omega-3-shows-benefits-ag 
$\underline{\text { ainst-oxidative-stress-Study }}$

[31] Meital, L.T., Windsor, M.T., Perissiou, M., Schulze, K., Magee, R., Kuballa, A., et al. (2019) Omega-3 Fatty Acids Decrease Oxidative Stress and Inflammation in Macrophages from Patients with Small Abdominal Aortic Aneurysm. Scientific Reports, 9, Aticle No. 12978. https://doi.org/10.1038/s41598-019-49362-Z

[32] Eslamloo, K., Xue, X., Hall, J.R., Smith, N.C., Caballero-Solares, A., Parrish, C.C., et al (2017) Transcriptome Profiling of Antiviral Immune and Dietary Fatty Acid Dependent Responses of Atlantic Salmon Macrophage-Like Cells. BMC Genomics, 18, Article No. 706. https://doi.org/10.1186/s12864-017-4099-2

[33] Wall, R., Ross, R.P., Fitzgerald, G.F. and Stanton, C. (2010) Fatty Acids from Fish: the Anti-Inflammatory Potential of Long Chain Omega-3 Fatty Acids. Nutrition Reviews, 68, 280-289. https://doi.org/10.1111/j.1753-4887.2010.00287.x

[34] Kang, K.W., Kim, S., Cho, Y.B., Ryu, S.R., Seo, Y.-J. and Lee, S.-M. (2019) Endogenous n-3 Polyunsaturated Fatty Acids Are Beneficial to Dampen CD8 ${ }^{+} \mathrm{T}$ Cell-Mediated Inflammatory Response upon the Viral Infection in Mice. International Journal of Molecular Sciences, 20, Article No. 4510. https://doi.org/10.3390/ijms20184510

[35] Mathru, M. (2009) Anti-Inflammatory Properties of Omega-3 Fatty Acids in Critical Illness: Novel Mechanisms and an Integrative Perspective. In: Yearbook of Anesthesiology and Pain Management, Vol. 2019, 147.

[36] Shahidi, F. and Ambigaipalan, P. (2018) Omega-3 Polyunsaturated Fatty Acids and Their Health Benefits. Annual Review of Food Science and Technology, 9, 345-381. https://doi.org/10.1146/annurev-food-111317-095850

[37] Wang, W., Yang, H., Johnson, D., Gensler, C., Decker, E. and Zhang, G. (2017) Chemistry and Biology of $\omega$-3 PUFA Peroxidation-Derived Compounds. Prostaglandins \& Other Lipid Mediators, 132, 84-91. https://doi.org/10.1016/j.prostaglandins.2016.12.004

[38] Awada, M., Soulage, C.O., Mevnier, A., Debard, C., Plaisancié, P., Benoit, B., et al. (2012) Dietary Oxidized n-3 PUFA Induce Oxidative Stress and Inflammation: Role of Intestinal Absorption of 4-HHE and Reactivity in Intestinal Cells. Journal of Lipid Research, 53, 2069-2080. https://doi.org/10.1194/jlr.M026179

[39] Bannenberg, G., Mallon, C., Edwards, H., Yeadon, D., Yan, K., Johnson, H. and Ismail, A. (2017) Omega-3 Long-Chain Polyunsaturated Fatty Acid Content and Oxidation State of Fish Oil Supplements in New Zealand. Scientific Reports, 7, Article No. 1488. https://doi.org/10.1038/s41598-017-01470-4

[40] Spite, M., Clària, J. and Serhan, C.N. (2014) Resolvins, Specialized Proresolving Lipid Mediators, and Their Potential Roles in Metabolic Diseases. Cell Metabolism, 19, 21-36. https://doi.org/10.1016/j.cmet.2013.10.006

[41] Herrera, B.S., Hasturk, H., Kantarci, A., Freire, M.O., Nguyen, O., Kansal, S., et al. (2015) Impact of Resolvin E1 on Murine Neutrophil Phagocytosis in Type 2 Diabetes. Infection and Immunity, 83, 792-801. https://doi.org/10.1128/IAI.02444-14

[42] Berliner, A.R. and Fine, D.M. (2011) There's Something Fishy about This Bleeding. NDT Plus, 4, 270-272. https://doi.org/10.1093/ndtplus/sfr046

[43] Stupin, M., Kibel, A., Stupin, A. Selthofer-Relatić, K., Matić, A., Mihalj, M., et al. (2019) The Physiological Effect of n-3 Polyunsaturated Fatty Acids (n-3 PUFAs) Intake and Exercise on Hemorheology, Micro vascular Function, and Physical Performance in Health and Cardiovascular Diseases; Is There an Interaction of Exercise and Dietary n-3 PUFA Intake? Frontiers in Physiology, 10, Article No. 1129. https://doi.org/10.3389/fphys.2019.01129 
[44] Hansen, J.B., Lyngmo, V., Svensson, B. and Nordøy, A. (1993) Inhibition of Exercise-Induced Shortening of Bleeding Time by Fish Oil in Familial Hypercholesterolemia (Type IIa). Arteriosclerosis and Thrombosis, 13, 98-104. https://doi.org/10.1161/01.ATV.13.1.98

[45] Sanders, T.A. and Roshanai, F. (1983) The Influence of Different Types of Omega 3 Polyunsaturated Fatty Acids on Blood Lipids and Platelet Function in Healthy Volunteers. Clinical Science, 64, 91-99. https://doi.org/10.1042/cs0640091

[46] Holub, B.J. (2002) Clinical Nutrition: 4. Omega-3 Fatty Acids in Cardiovascular care. Journal of Applied Mathematics and Computing, 166, 608-615.

[47] Munk-Begtrup, K.M., Krag, A.E. and Hvas, A.M. (2017) No Impact of Fish Oil Supplements on Bleeding Risk: A Systematic Review. Danish Medical Journal, 64, Article No. A5366.

[48] Kris-Etherton, P.M., Harris, W.S. and Appel, L.J. (2003) Omega-3 Fatty Acids and Cardiovascular Disease: New Recommendations from the American Heart Association. Arteriosclerosis, Thrombosis, and Vascular Biology, 23, 151-152. https://doi.org/10.1161/01.ATV.0000057393.97337.AE

[49] Leonhardt, M. and Langhans, W. (2007) Lipid Metabolism: Its Role in Energy Regulation and Obesity. In: Henry, C.J.K., Ed., Novel Food Ingredients for Weight Control: Woodhead Publishing Series in Food Science, Technology and Nutrition, Woodhead Publishing, Cambridge, 3-27. https://doi.org/10.1533/9781845693114.1.3

[50] Telle-Hansen, V.H., Gaundal, L. and Myhrstad, M. (2019) Polyunsaturated Fatty Acids and Glycemic Control in Type 2 Diabetes. Nutrients, 11, Article No. 1067. https://doi.org/10.3390/nu11051067

[51] Landmark, K. and Aursnes, I. (2004) Mercury, Fish, Fish Oil and the Risk of Cardiovascular Disease. Tidsskrift for Den norske legeforening, 124, 198-200.

[52] Hu, X.F., Laird, B.D. and Chan, H. (2017) Mercury Diminishes the Cardiovascular protective effect of Omega-3 Polyunsaturated Fatty Acids in the Modern Diet of Inuit in Canada. Environmental Research, 152, 470-477. https://doi.org/10.1016/j.envres.2016.06.001

[53] Guallar, E., Sanz-Gallardo, M.I., Veer, P.V.T., Bode, P., Aro, A., Gómez-Aracena, J., et al. (2002) Mercury, Fish Oils, and the Risk of Myocardial Infarction. N. Engl. J. Med, 347, 1747-1754. https://doi.org/10.1056/NEJMoa020157

[54] Bergkvist, C., Berglund, M., Glynn, A., Julin, B., Wolk, A. and Åkesson, A. (2016) A Dietary Exposure to Polychlorinated Biphenyls and Risk of Myocardial Infarction in Men-A Population-Based Prospective Cohort Study. Environment International, 88, 9-14. https://doi.org/10.1016/j.envint.2015.11.020

[55] GISSI-HF Investigators (2008) Effect of n-3 Polyunsaturated Fatty Acids in Patients with Chronic Heart Failure (the GISSI-HF Trial): A Randomized, Double-Blind, Placebo-Controlled Trial. Randomized Control Trial. Lancet, 372, 1223-1230. https://doi.org/10.1016/S0140-6736(08)61239-8

[56] Scicali, R., Di Pino, A., Piro, S., Rabuazzo, A.M. and Purrello, F. (2020) May Statins and PCSK9 Inhibitors Be Protective from COVID 19 in Familiar Hypercholesterolemia. Nutrition, Metabolism \& Cardiovascular Diseases, 30, 1068-1069. https://doi.org/10.1016/j.numecd.2020.05.003

[57] Davignon, J. (2004) Beneficial Cardiovascular Pleiotropic Effects of Statins. Circulation, 109, III-39-III-43. https://doi.org/10.1161/01.CIR.0000131517.20177.5a

[58] Genser, B., Grammer, T.B., Stojakovic, T., Siekmeier, R. and März, W. (2008) Effect of HMG CoA Reductase Inhibitors on Low-Density Lipoprotein Cholesterol and C-Reactive Protein: Systematic Review and Meta-Analysis. International Journal of 
Clinical Pharmacology \& Pharmacotherapy, 46, 497-510. https://doi.org/10.5414/CPP46497

[59] Sahebkar, A., Serban, C., Ursoniu, S., Mikhailidis, D.P., Undas, A., Lip, G.Y.H., et al. (2016) The Impact of Statin Therapy on Plasma Levels of Von Willebrand Factor Antigen. Systematic Review and Meta-Analysis of Randomized Placebo Controlled Trials. Journal of Thrombosis and Haemostasis, 115, 520-532. https://doi.org/10.1160/th15-08-0620

[60] Sahebkar, A., Kotani, K., Serban, C., Ursoniu, S., Mikhailidis, D., Jones, S.R., Ray, K.K., et al. (2015) Statin Therapy Reduce Plasma Endothelin-1 Concentrations: A Meta-Analysis of 15 Randomized Controlled Trials. Atherosclerosis, 241, 433-434. https://doi.org/10.1016/j.atherosclerosis.2015.05.022

[61] Arancibia, S.A., Beltran, C.J., Aguirre, I.M., Silva, P., Peralta, A.L., Malinarich, F., et al. (2007) Toll-Like Receptors Are Key Partici Pants in Innate Immune Responses. Biological Research, 40, 97-112. https://doi.org/10.4067/S0716-97602007000200001

[62] Yuan, S. (2015) Statins May Decrease the Fatality Rate of Middle East Respiratory Syndrome Infection. MBio, 6, Article No. 1115. https://doi.org/10.1128/mBio.01120-15

[63] Yuan, X., Deng, Y., Guo, X., Shang, J., Zhu, D. and Liu, H. (2014) Atorvastatin Attenuates Myocardial Remodeling Induced by Chronic Intermittent Hypoxia in Rats: Partly Involvement of TLR-4/ MYD88 Pathway. Biochemical and Biophysical Research Communications, 446, 292-297. https://doi.org/10.1016/j.bbrc.2014.02.091

[64] Castiglione, M., Chiriaco, M., Emdin, M., Taddei, S. and Vergaro, G. (2020) Statin Therapy in COVID-19 Infection. European Heart Journal-Cardiovascular Pharmacotherapy, 6, 258-259. https://doi.org/10.1093/ehjcvp/pvaa042

[65] De Spiegeleer, A., Bronselaer, A., Teo, J.T., Byttebier, G., De Tré, G., Belmans, L., et al. (2020) The Effects of ARBs, ACEIs and Statins on Clinical Outcomes of COVID-19 Infection among Nursing Home Residents. Journal of the American Medical Directors Association, 21, 909-914.E2.

https://doi.org/10.1016/j.jamda.2020.06.018

[66] Jukema, R.A., Ahmed, T.A.N. and Tardif, J. (2019) Does Low-Density Lipoprotein Cholesterol Induce Inflammation? If So, Does It Matter? Current Insights and Future Perspectives for Novel Therapies. BMC Medicine, 17, Article No. 197. https://doi.org/10.1186/s12916-019-1433-3

[67] Kleemann, R., Verschuren, L., De Rooi, B.J., Lindeman, J., de Maat, M.M., Szalai, A.J., et al. (2004) Evidence for Anti-Inflammatory Activity of Statins and PPAR-Alpha Activators in Human C-Reactive Protein Transgenic Mice in-Vivo and in Cultured Human Hepatocytes in Vitro. Blood, 103, 4188-4194.

https://doi.org/10.1182/blood-2003-11-3791

[68] Albert, M.A., Danielson, E., Rifai, N., Ridker, P.M. and Prince Investigators (2001) Effect of Statin Therapy on C-Reactive Protein Levels: The Pravastatin Inflammation/CRP Evaluation (PRINCE): A Randomized trial and Cohort Study. Journal of The American Medical Association, 286, 64-70.

https://doi.org/10.1001/jama.286.1.64

[69] Ridker, P.M., Danielson, E., Fonseca, F.A.H., Genest, J., Gotto Jr., A.M., Kastelein, J.J.P., et al. (2008) Rosuvastatin to Prevent Vascular Events in Men and Women with Elevated C Reactive Protein. New England Journal of Medicine, 359, 2195-2207. https://doi.org/10.1056/NEJMoa0807646

[70] Klok, F.A., Kruip, M.J.H.A., Van der Meer, N.J.M., Arbous, M.S., Gommers, D.A., Kant, K.M., Kaptein, F.H., et al. (2020) Incidence of Thrombotic Complications in 
Critically Ill ICU Patients with COVID-19. Thrombosis Research, 191,145-147. https://doi.org/10.1016/j.thromres.2020.04.013

[71] Lin, Z., Kumar, A., Sen Banerjee, S., Staniszewski, K., Parmar, K., Vaughan, D.E., et al. (2005) Kruppel-Like Factor 2 (KLF2) Regulates Endothelial Thrombotic Function. Circulation Research, 96, e48-e57. https://doi.org/10.1161/01.RES.0000159707.05637.a1

[72] Glende, J., Schwegmann-Wessels, C., Al-Falah, M., Pfefferle, S., Qu, X., Deng, H., et al. (2008) Importance of Cholesterol-Rich Membrane Micro Domains in the Interaction of the S Protein of SARS-Coronavirus with the cellular Receptor Angiotensin-Converting Enzyme 2. Virology, 381, 215-221. https://doi.org/10.1016/j.virol.2008.08.026

[73] Li, Y.H., Wang, Q.X., Zhou, J.W., Chu, X.M., Man, Y.L., Liu, P., et al. (2013) Effects of Rosuvastatin on Expression of Angiotensin-Converting Enzyme 2 after Vascular Balloon Injury in Rats. Journal of Geriatric Cardiology, 10, 151-158.

[74] Ghosal, S., Mukherjee, J.J., Sinha, B. and Gangopadhyay, K.K. (2020) The Effect of Angiotensin Converting Enzyme Inhibitors and Angiotensin Receptor Blockers on Death and Severity of Disease in Patients with Coronavirus Disease 19 (COVID-19): A Meta-Analysis. Med-Rxiv.

[75] Frost, F.J., Petersen, H., Tollestrup, K. and Skipper, B. (2007) Influenza and COPD Mortality Protection as Pleiotropic, Dose-Dependent Effects of Statins. Chest, 131, 1006-1012. https://doi.org/10.1378/chest.06-1997

[76] Hu, X. and Chen, D. (2020) Low Serum Cholesterol Level among Patients with COVID-19 Infection in Wenzhou, China. Lancet. https://doi.org/10.2139/ssrn.3544826

[77] Ravnskov, U. (2020) Cholesterol-Lowering Treatment May Be a Major Cause of Serious Covid-19 Infections. BMJ, 368, Article No. 1182.

[78] Jacobs, D., Blackburn, H., Higgins, M., Reed, D., Iso, H., McMillan, G., et al. (2020) Report of the Conference on Low Blood Cholesterol: Mortality Associations. Circulation, 86, 1046-1060. https://doi.org/10.1161/01.CIR.86.3.1046

[79] Tomaszewski, M., Stepien, K.M., Tomaszewska, J. and Czuczwar, S.J. (2011) Statin-Induced Myopathies. Pharmacological Reports, 63, 859-866.

https://doi.org/10.1016/S1734-1140(11)70601-6

[80] Thomas, W.W. (2005) Management of the Statin, Intolerant Patient Current. Perspectives in Cardiology, 27, 26-28.

[81] Mao, L., Jin, H., Wang, M., Hu, Y., Chen, S., He, Q., et al. (2020) Neurologic Manifestations of Hospitalized Patients with Coronavirus Disease 2019 in Wuhan, China. JAMA Neurology, 77, 683-690. https://doi.org/10.1001/jamaneurol.2020.1127

[82] Ward, N.C., Watts, G.F. and Eckel, R.H. (2019) Statin Toxicity-Mechanistic Insights and Clinical Implications. Circulation Research, 124, 328-350. https://doi.org/10.1161/CIRCRESAHA.118.312782

[83] Pawlos, A., Niedzielsky, M., Broncel, M., et al. (2021) Liverpool COVID-19 Drug Interactions.

[84] Abu-Farha, M., Thanaraj, T., Qaddoumi, M., Hashem, A., Abubaker, J. and Al-Mulla, F. (2020) The Role of Lipid Metabolism in COVID-19. Virus Infection and as Drug Target. International Journal of Molecular Sciences, 21, Article No. 3544. https://doi.org/10.3390/ijms21103544

[85] Malvina, H. (2020) What about COVID 19 and Arachidonic Acid Pathway? Euro- 
pean Journal of Clinical Pharmacology, 76, 1501-1504.

https://doi.org/10.1007/s00228-020-02941-w

[86] Singer, P. and Shapiro, H. (2009) Enteral Omega-3 in Acute Respiratory Distress Syndrome. Current Opinion in Clinical Nutrition and Metabolic Care, 12, 123-128. https://doi.org/10.1097/MCO.0b013e328322e70f

[87] Li, C., Bo, L., Liu, W., Lu, X. and Jin, F. (2015) Enteral Immunomodulatory Diet (Omega-3 Fatty Acid, g-Linolenic Acid and Antioxidant Supplementation) for Acute Lung Injury and Acute Respiratory Distress Syndrome: An Updated Systematic Review and Meta-Analysis. Nutrients, 7, 5572-5585.

https://doi.org/10.3390/nu7075239

[88] Pontes-Arruda, A., De Michele, S., Seth, A. and Singer, P. (2008) The Use of an Inflammation-Modulating Diet in Patient with Acute Lung Injury or ARDS: A Metanalysis of Outcome Data. Journal of Parenteral and Enteral Nutrition, 32, 595-605. https://doi.org/10.1177/0148607108324203

[89] Dunshianthan, A., Cusack, R., Burgess, V.A., Grocott, M.P. and Calder, P.C. (2019) Immunonutrition for Acute Respiratory Distress Syndrome (ARDS) in Adults. Cochrane Database of Systematic Reviews 2019, No. 1, Article No. CD012041.

[90] Zabetakis, I., Lordan, R., Norton, C. and Tsoupras, A. (2020) The Inflammation Link and Role of Nutrition in Potential Mitigation. Nutrients, 12, Article No. 1466. https://doi.org/10.3390/nu12051466

[91] Michael, B.J. and Barrientos, R.M. (2020) The Impact of Nutrition on COVID-19 Susceptibility and Long-Term Consequences. Brain, Behavior, and Immunity, 87, 53-54. https://doi.org/10.1016/j.bbi.2020.04.040

[92] Ghaffari, S., Roshanravan, E., Tutunchi, H., Ostadrahimi, A., Pouraghaei, M. and Kafil, B. (2020) Oleoylethanolamide, a Bioactive Lipid Amide as a Promising Treatment Strategy for Coronavirus COVID19. Archives of Medical Research, 51, 464-467. https://doi.org/10.1016/j.arcmed.2020.04.006

[93] Undarti, D.N. (2020) Bioactive Lipids as Mediators of the Beneficial Actions of Mesenchymal Stem Cells in COVID19. Aging and Disease, 11, 746-755.

https://doi.org/10.14336/AD.2020.0521

[94] Langlois, P.L., D’Aragon, F., Hardy, G. and Manzanares, W. (2019) Omega-3 Polyunsaturated Fatty Acids in Critically Ill Patients with Acute Respiratory Distress Syndrome: A Systematic Review and Meta-Analysis. Nutrition, 61, 84-92. https://doi.org/10.1016/j.nut.2018.10.026

[95] Darwesh, M.A., Bassiouni, W., Sosnowsky, K.D. and Seubert, J.M. (2021) Can N-3 Polyunsaturated Fatty Acids Be Considered a Potential Adjuvant Therapy for COVID-19-Associated Cardiovascular Complications? Pharmacology \& Therapeutics, 219, Article ID: 107703. https://doi.org/10.1016/j.pharmthera.2020.107703

[96] Rossi, R., Talarico, M., Coppi, F. and Boriani, G. (2020) Protective Role of Statins in COVID-19: Importance of Pharmacokinetic Characteristics Rather than Intensity of Action. Internal and Emergency Medicine, 15, 1573-1576. https://doi.org/10.1007/s11739-020-02504-y

[97] Ferrari, F. and Santos, D.R. (2021) Statins and COVID-19: To Suspend or Not to Suspend? That Is the Question! Arquivos Brasileiros de Cardiologia, 116, 147-152.

[98] Tan, W.T., Young, B.E., Lye, D.C., Chew, D.E.K. and Dalan, R. (2020) Statin Use Is Associated with Lower Disease Severity in COVID-19 Infection. Scientific Reports, 10, Article No. 17458. https://doi.org/10.1038/s41598-020-74492-0

[99] De Spiegeleer, A., Bronselaer, A., Teo, J.T., Byttebier, G., De Tré, G., Belmans, L., et 
al. (2020) The Effects of ARBs, ACEis, and Statins on Clinical Outcomes of COVID-19 Infection among Nursing Home Residents. Journal of the American Medical Directors Association, 21, 909-914.

https://doi.org/10.1016/j.jamda.2020.06.018

[100] Zhang, X.J., Qin, J.J., Cheng, X., Shen, L., Zhao, Y.-C., Yuan, Y., et al. (2020) In-Hospital Use of Statins Is Associated with a Reduced Risk of Mortality among Individuals with COVID-19. Cell Metabolism, 32, 176-187. E4.

https://doi.org/10.1016/j.cmet.2020.06.015

[101] Rodriguez-Nava, G., Trelles-Garcia, D.P., Yanez-Bello, M.A., Chung, C.W., Trelles-Garcia, V.P. and Friedman, H.J. (2020) Atorvastatin Associated with Decreased Hazard for Death in COVID-19 Patients Admitted to an ICU: A Retrospective Cohort Study. Critical Care, 24, Article No. 429.

https://doi.org/10.1186/s13054-020-03154-4

[102] Daniels, L.B., Sitapati, A.M., Zhang, J, Zou, J., Bui, Q.M., Ren, J., et al. (2020) Relation of Statin Use Prior to Admission to Severity and Recovery among COVID-19 in Patients. The American Journal of Cardiology, 136, 149-155.

https://doi.org/10.1016/j.amjcard.2020.09.012

[103] Song, S.L., Hays, S.B., Panton, C.E., Mylona, E.K., Kalligeros, M., Shehadeh, F. and Mylonakis, E. (2020) Statin Use Is Associated with Decreased Risk of Invasive Mechanical Ventilation in COVID-19 Patients: A Preliminary Study. Pathogens, 9, Article No. 759. https://doi.org/10.3390/pathogens9090759

[104] Novack, V., MacFadyen, J., Malhotra, A., Almog, Y., Glynn, R.J. and Ridker, P.M. (2012) The Effect of Rosuvastatin on Incident Pneumonia: Results from the JUPITER Trial. Canadian Medical Association Journal, 184, E367-E372. https://doi.org/10.1503/cmaj.111017

[105] Helms, J., Tacquard, C., Severac, F., Leonard-Lorant, I., Ohana, M., Delabranche, X., et al. (2020) High Risk of Thrombosis in Patients with Severe SARS-CoV-2 Infection: A Multicenter Prospective Cohort Study. Intensive Care Medicine, 46, 1089-1098. https://doi.org/10.1007/s00134-020-06062-x

[106] Glynn, R.J., Danielson, E., Fonseca, F.A., Genest, J., Gotto Jr., A.M., Kastelein, J.J.P., et al. (2009) A Randomized Trial of Rosuvastatin in the Prevention of Venous Thromboembolism. The JUPITER Trial. New England Journal of Medicine, 360, 1851-1861. https://doi.org/10.1056/NEJMoa0900241

[107] Kunutsor, S.K., Seidu, S. and Khunti, K. (2017) Statins and Primary Prevention of Venous Thromboembolism: A Systematic Review and Meta-Analysis. The Lancet Haematology, 2, E83-E93. https://doi.org/10.1016/S2352-3026(16)30184-3

[108] Adams, N.B., Lutsey, P.L., Folsom, A.R., Herrington, D.H., Sibley, C.T., Zakai, N.A., et al. (2013) Statin Therapy and Levels of Haemostatic Factors in a Healthy Population: The Multi-Ethnic Study of Atherosclerosis. Journal of Thrombosis and Haemostasis, 11, 1078-1084. https://doi.org/10.1111/jth.12223

[109] Rodriguez, A.L., Wojcik, B.M., Wrobleski, S.K., Myers Jr., D.D., Wakefield, T.W. and Diaz, J.A. (2012) Statins, Inflammation and Deep Vein Thrombosis: A Systematic Review. Journal of Thrombosis and Thrombolysis, 33, 371-382.

https://doi.org/10.1007/s11239-012-0687-9

[110] Das, U.N. (2013) n-3 Fatty Acids, $\gamma$-Linolenic Acid, and Antioxidants in Sepsis. Das Critical Care, 17, Article No. 312. https://doi.org/10.1186/cc12574

[111] European Society of Cardiology (2020) ESC Guidance for the Diagnosis and Management of CV Disease during the COVID-19 Pandemic. European Society of Cardiology, Sophia Antipolis, Brussels. 
[112] Greenhalgh, T., Koh, G. and Car, J. (2020) Covid-19: A Remote Assessment in Primary Care. BMJ, 368, Article No. 1182. https://doi.org/10.1136/bmj.m1182

[113] Cholesterol Treatment Trialists' (CTT) Collaboration (2010) Efficacy and Safety of More Intensive Lowering of LDL Cholesterol: A Meta-Analysis of Data from 170,000 Participants in 26 Randomized Trials. Lancet, 376, 1670-1681.

https://doi.org/10.1016/S0140-6736(10)61350-5

[114] Platelet Receptor Inhibition in Ischemic Syndrome Management Investigators (1998) A Comparison of Aspirin Plus Tirofiban with Aspirin Plus Heparin for Unstable Angina: The Platelet Receptor Inhibition in Ischemic Syndrome Management (PRISM) Study Investigators. New England Journal of Medicine, 338, 1498-1505. https://doi.org/10.1056/NEJM199805213382103

[115] Heeschen, C., Hamm, C.W., Laufs, U., Snapinn, S., Böhm, M. and White, H.D. (2002) Withdrawal of Statins Increases Event Rates in Patients with Acute Coronary Syndromes. Circulation, 105, 1446-1452.

https://doi.org/10.1161/01.CIR.0000012530.68333.C8

[116] Kow, S.C. and Syed, S.H. (2020) Meta-Analysis of Effect of Statins in Patient with COVID-19. American Journal of Cardiology, 134, 153-155.

https://doi.org/10.1016/j.amjcard.2020.08.004

[117] Vittielo, A., La Porta, R. and Ferrara, F. (2020) Correlation between the Use of Statins and COVID-19: What Do We Know? BMJ Evidence-Based Medicine. https://doi.org/10.1136/bmjebm-2020-111589 